\title{
Estimating the Effect of Climate Internal Variability and Source of Uncertainty in Climate-Hydrological Projections in a Representative Watershed of Northeastern China
}

\author{
Wenjun Cai \\ Taiyuan University of Technology \\ Xueping Zhu ( $\nabla$ xpzhu01@163.com ) \\ Taiyuan University of Technology \\ Xuehua Zhao \\ Taiyuan University of Technology \\ Yongbo Zhang \\ Taiyuan University of Technology
}

\section{Research Article}

Keywords: climate change, GCMs, climate-hydrological projections, uncertainty contributor, climate internal variability, ANOVA

Posted Date: October 20th, 2021

DOI: https://doi.org/10.21203/rs.3.rs-849739/v1

License: (c) (1) This work is licensed under a Creative Commons Attribution 4.0 International License.

Read Full License 
Estimating the effect of climate internal variability and source of uncertainty in climate-hydrological projections in a representative watershed of Northeastern China

Wenjun Cai $^{{ }^{1}} \quad$ Xueping Zhu ${ }^{1, *} \quad$ Xuehua Zhao ${ }^{I} \quad$ Yongbo Zhang ${ }^{I}$

1 College of Water Resource and Engineering, Taiyuan University of Technology, Taiyuan 030024, China;

Corresponding authore-mail address: xpzhu01@163.com

\section{Abstract:}

The decomposition and quantification of uncertainty sources in ensembles of climate-hydrological simulation chains is a key issue in climate impact researches. The mainly objectives of this study partitioning climate internal variability (CIV) and uncertainty sources in the climate-hydrological projections simulation process, the climate simulation process formed by six downscaled GCMs under two emission scenarios called GCMs-ES simulation chain, the hydrological simulation process add one calibrate Soil and Water Assessment Tool (SWAT) model called GCMs-ES-HM simulation chain. The CIV and external forcing of climate projections are investigated in each GCMs-ES simulation chain. The CIV of precipitation and ET are large in rainy season, and the single-to-noise ratio (SNR) are also relatively high in rainy season. Furthermore, the uncertainty decomposed frameworks based on analysis of variance (ANOVA) are established. The CIV and GCMs are the dominate contributors of runoff in rainy season. It worth noting the CIV can propagate from precipitation and ET to runoff projections. In additional, the hydrological model parameters are the third uncertainty contributor of runoff, which embody the hydrological model simulate process play important role in hydrological projections in future. The findings of this study advised that the uncertainty is complex in hydrological, hence, it is meaning and necessary to estimate the uncertainty in climate simulation process, the uncertainty analysis results can provide effectively efforts to reduce uncertainty and then give some positive suggestions to stakeholders for adaption countermeasure under climate change.

Key words: climate change; GCMs; climate-hydrological projections; uncertainty contributor; climate internal variability; ANOVA

\section{Introduction}

Hydrology cycle has been significantly impacted by climate change, a large number of studies have assessed the future climate projections and quantified corresponding impacts on hydrological regimes (Vaghef et al. 2019; Anjum et al. 2019; Zhang et al. 2016; Wang et al. 2018). As the 
primary tools for providing the future climate variables in changing environment, GCMs are employed to drive HMs, such as the SWAT to obtain the future runoff projections in recently studies (Wang et al. 2020). GCM can be used to simulated the general circulation of the earth's atmosphere, which can provide the credible information from past to future meteorological data (Zhang et al. 2016). Generally, the assessments of the climate change on hydrological regimes are to drive a hydrological model with an ensemble of GCMs. Statistical downscaling methods (SDMs) and dynamic downscaling methods are used to obtain a fine spatial resolution of GCMs at watershed scales. SDMs are effectively and widely used to linkage the gaps of the spatial and temporal resolution exist between GCMs and HMs (Wang et al. 2020). Future runoff process is commonly obtained with a sequence of climate simulation process under various emission scenarios, however, a large body of uncertainties exist in the process of estimating hydrological projections under climate change impacts (Shen et al. 2018). The different aspects of uncertainty in the model chain can be categorized as: (I) climate simulation uncertainty; (II) hydrological simulation uncertainty. (Byun et al. 2019; Li et al. 2015; Chen et al. 2016; Ficklin et al. 2016; Zhang et al. 2013; Lee et al. 2016; Nóbrega et al. 2011).

For climate simulation uncertainty, there are three kinds of uncertainty sources:(i) external forcing, (ii) model response uncertainty, and (iii) internal variability (Hawkins and Sutton 2011; Deser et al. 2012). The external forcing uncertainty represents arises from the anthropogentic forcing employed in emission scenarios (Yu et al. 2020). Model response uncertainty is explanation as the different climate change model may output different responses for the same forced information. The internal uncertainty explains as the natural variability of the precipitation and temperature etc., which describes the natural process in the atmosphere, ocean, and their couple uncertainties (Pesce et al. 2019). The inherently chaotic internal processes in the climate system are cascading to the hydrological processes (Lafaysse et al. 2014). The similarly larger-scale atmosphere circulation may lead to different local-scale climate projections, this local-scale of internal variability can be dominantly accounted by the downscaling method (Lafaysse et al. 2014). Take the statistical downscaling method for example, it uses a stochastic process to produces climate projections at finer scales for a certain large-scale pattern, and the performance of estimating internal variability, moreover, the internal variability plays a significant important role in climate change projections (Doi and Kim 2020). On the base of independently of 
the external forcing, the internal variability of climate projections has been analyzed by many studies to estimate the uncertainty range of a chosen forced response and obtain a robust detection of climate change effects (Steinschneider et al. 2015; Schindler et al. 2015; Nerantzaki et al. 2020).

For the hydrological simulation uncertainty which included input data, hydrological model structure and model parameters (Lee et al. 2016; Xue et al. 2014; Yen et al. 2014; Nerantzaki et al. 2019; Zhang et al. 2013; Qin et al. 2014; Zhang et al. 2013; Lee et al. 2016; Galavi et al. 2020). Among the hydrological modeling uncertainty, the uncertainty from model structure mainly caused by the mathematical model, it is able to portray the real characteristic of the basin (Gupta A and Govindaraju R S 2019) and it can be expressed by parameters. The contribution of parameters uncertainties is significant impacts in the model output, the different parameters may due to the runoff changing in opposite directions (Zhang et al. 2019). In addition, parameter uncertainty is relatively to control by some conceptual or empirical parameters and an appropriate calibration method (Wu and Chen 2015). The inappropriate estimation of main parameters may result in non-negligible uncertainty, for this reason, parameters uncertainty has received most attention of previous studies (Nerantzaki et al. 2019). There are several methods for quantifying the model parameters uncertainty analysis, such as the Sequential Uncertainty Fitting algorithm (SUFI2) (Abbaspour KC et al. 2011), the Generalized Likelihood Uncertainty Estimation (GLUE) (Beven and Binley 1992) and the Parameter Solution (ParaSol) (Griensven and Meixner 2006), these three techniques are widely been applied in sensitivity and uncertainty analysis of parameters in hydrological model. The technology of SUFI2 shows the robust ability in estimation the parameter uncertainty (Zhao et al. 2018; Xue et al. 2014).

In order to obtain a robust detection of climate change effects and give some useful suggestions to practical decision making, this manuscript focus on analyzing the changing of precipitation, temperature, ET and runoff under climate change, and evaluating the source of uncertainty contribution in the two simulations chains.

To segregate the uncertainty contribution of individual sources in hydrological simulated chain, Bosshard et al. (2013) quantified the uncertainties contributions of an ensemble of hydrological climate impact projections by using the ANOVA method. The ANOVA technique has fewer assumptions as compared to other uncertainty analysis methods, such as Bayesian methods and 
GULE (Vaghef et al. 2019). In recently hydrological application, the assessment framework based on ANOVA has been used to investigated the individual and interaction uncertainty from different sources (Chawla et al. 2018; Qi et al. 2016; Kujawa et al. 2020; Keller et al. 2019; Wang et al. 2020). However, the different kinds of uncertainty sources have not been estimated equally in previous researches. They mainly aim on decomposition the GCMs, emission scenarios, downscaling method, hydrological model structure and parameter for simulation chains (Kujawa et al. 2020; Shi et al. 2020; Keller et al. 2019). Moreover, to investigate the role of the internal variability in the overall climate change uncertainty can provide more useful information to uncertainty estimating of simulation chains and establish more comprehensive framework of uncertainty analysis (Liu et al. 2012; Schindler et al. 2015; Steinschneider et al. 2015; Nerantzaki et al. 2020). Therefore, comprehensive and systematical investigating the hydrological climate change impact and estimating different sources of uncertainty is worth and necessary.

The mainly aim of this study is:(1) to analyze the precipitation, temperature, ET and runoff projections changing under climate change. (2) to estimate the role of internal variability and external forcing on the climate-hydrological projections. (3) to quantify the source of uncertainty contribution on the overall uncertainty. (4) to confirm the important influence factors and uncertainty source of runoff. The uncertainty decomposition framework of this study shows in Fig.1.

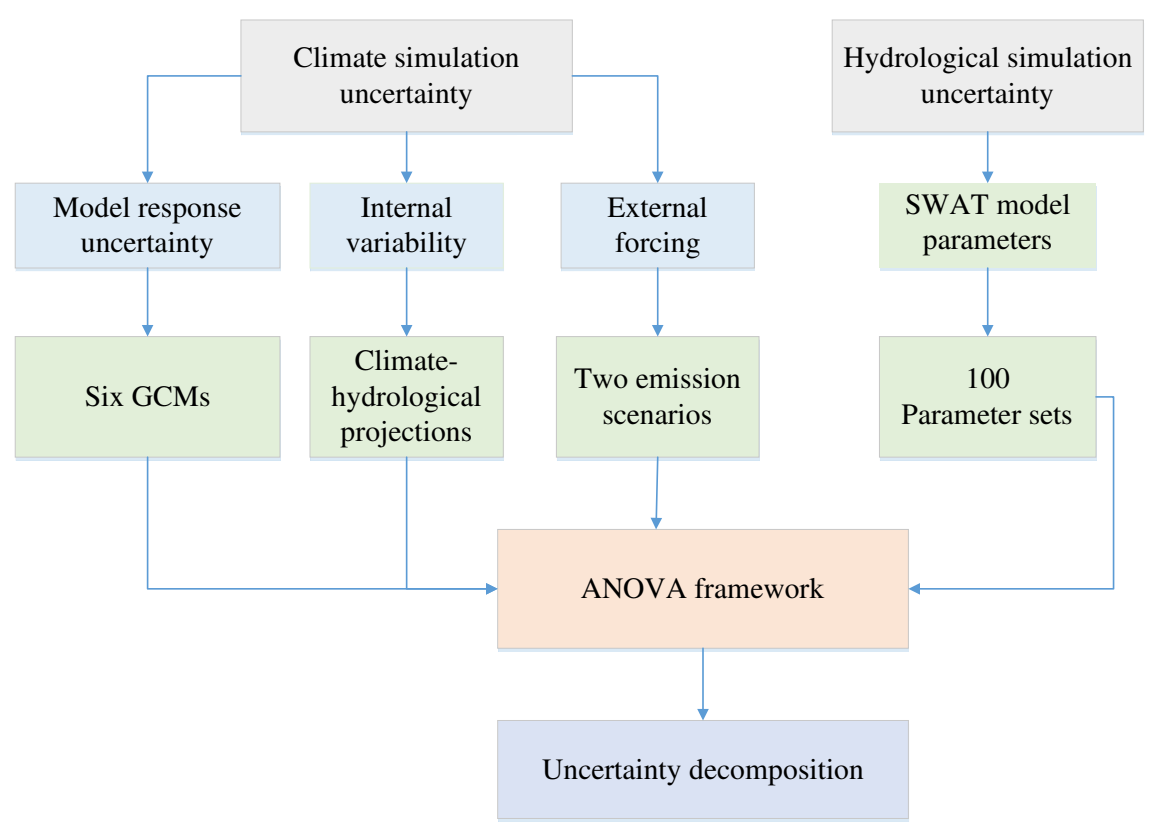

Fig.1. Flowchart of the uncertainty decomposition framework of this study

113 For this purpose, this manuscript combined six GCMs models under two Representative 
114 Concentration Pathways (RCPs), which have been based on the fifth phase of the Coupled Model

115 Intercomparison Project (CMIP5). These climate change scenarios were downscaled by the 116 statistical downscaling method. Morphing (Belcher et al. 2019) and then a widely used 117 hydrological model SWAT was used to runoff simulation, the SUFI-2 (Abbaspour et al. 2011) 118 uncertainty approach for capturing the relatively uncertainty of SWAT model parameters. The 119 findings of this research may provide some meaningful suggestions on hydrological climate 120 change impacts and presents a methodology for partitioning uncertainty sources of runoff 121 projections in a representative watershed in Northeastern of China.

\section{Study area and data}

\subsection{Study area}

The Biliu River basin is located in the Northeastern of China spans $39.54^{\circ}$ to $40.35^{\circ} \mathrm{N}$ in latitude and $122.29^{\circ}$ to $122.93^{\circ} \mathrm{E}$ in longitude with an approximate area of $2085 \mathrm{~km}^{2}$ (Fig.2). The Biliu River Reservoir was built in 1975 and the storage of it is $9.34 \times 10^{8} \mathrm{~m}^{3}$. The mainly utility of this reservoir is water supply for nearby big cities and cropland irrigation. Another reservoir, called Yushi Reservoir, which was built in 2001 and located in the upstream of Biliu River, with a storage capacity of $0.89 \times 10^{8} \mathrm{~m}^{3}$ and a drainage area of $313 \mathrm{~km}^{2}$. Because of the reservoir supplies water to the outside of the basin, thus, the impact of Yushi Reservoir should be considered in the hydrological model. This study area has the characterized of temperate, monsoon marine climate, and with the rainy season from June to September. The mean annual precipitation is $746 \mathrm{~mm}$, the average annual temperature is $8.40^{\circ} \mathrm{C}$ to $10.3^{\circ} \mathrm{C}$, and the maximum and minimum temperatures are $35.8^{\circ} \mathrm{C}$ and $-23.5^{\circ} \mathrm{C}$, respectively.

\subsection{Data and climate change scenarios}

The historical observed daily precipitation and daily runoff data were available form1978-2004, the monthly precipitation and runoff data were form 1958-2011, which were obtain from the Biliu River Reservoir administration and Hydrology Bureau of Liaoning Province. The DEM, land-use map, and soil type map are obtained from the Data Center for Resources and Environmental Science, Chinese Academy of Sciences.

The climate data were used output from six GCMs in CMIP5 under RCP4.5 and RCP8.5 emission scenarios: ACCESS1-0, BCC-CSM1.1(m), CESM1-BGC, CESM1-CAM5, CMCC-CM, 
143 MPI-ESM-MR (Table1). The climate data were extracted for 1980-2004 period, 2041-2065 period

144 and 2066-2090 period, which defined as reference period, 2050s and 2080s two future period.

145

146

147
Table 1 Description of CMIP5 climate models and scenarios

\begin{tabular}{lccc}
\hline Climate Models & Country & Resolution & Scenarios \\
\hline ACCESS1.0 & Australia & $1.88^{\circ} \times 2.48^{\circ}$ & RCP4.5, RCP8.5 \\
BCC-CSM1.1(m) & China & $1.13^{\circ} \times 1.13^{\circ}$ & RCP4.5, RCP8.5 \\
CESM1(BGC) & USA & $1.3^{\circ} \times 0.9^{\circ}$ & RCP4.5, RCP8.5 \\
CESM1(CAM5) & USA & $1.3^{\circ} \times 0.9^{\circ}$ & RCP4.5, RCP8.5 \\
CMCC-CM & Italy & $0.75^{\circ} \times 0.75^{\circ}$ & RCP4.5, RCP8.5 \\
MPI-ESM-MR & Germany & $1.88^{\circ} \times 1.88^{\circ}$ & RCP4.5, RCP8.5 \\
\hline
\end{tabular}

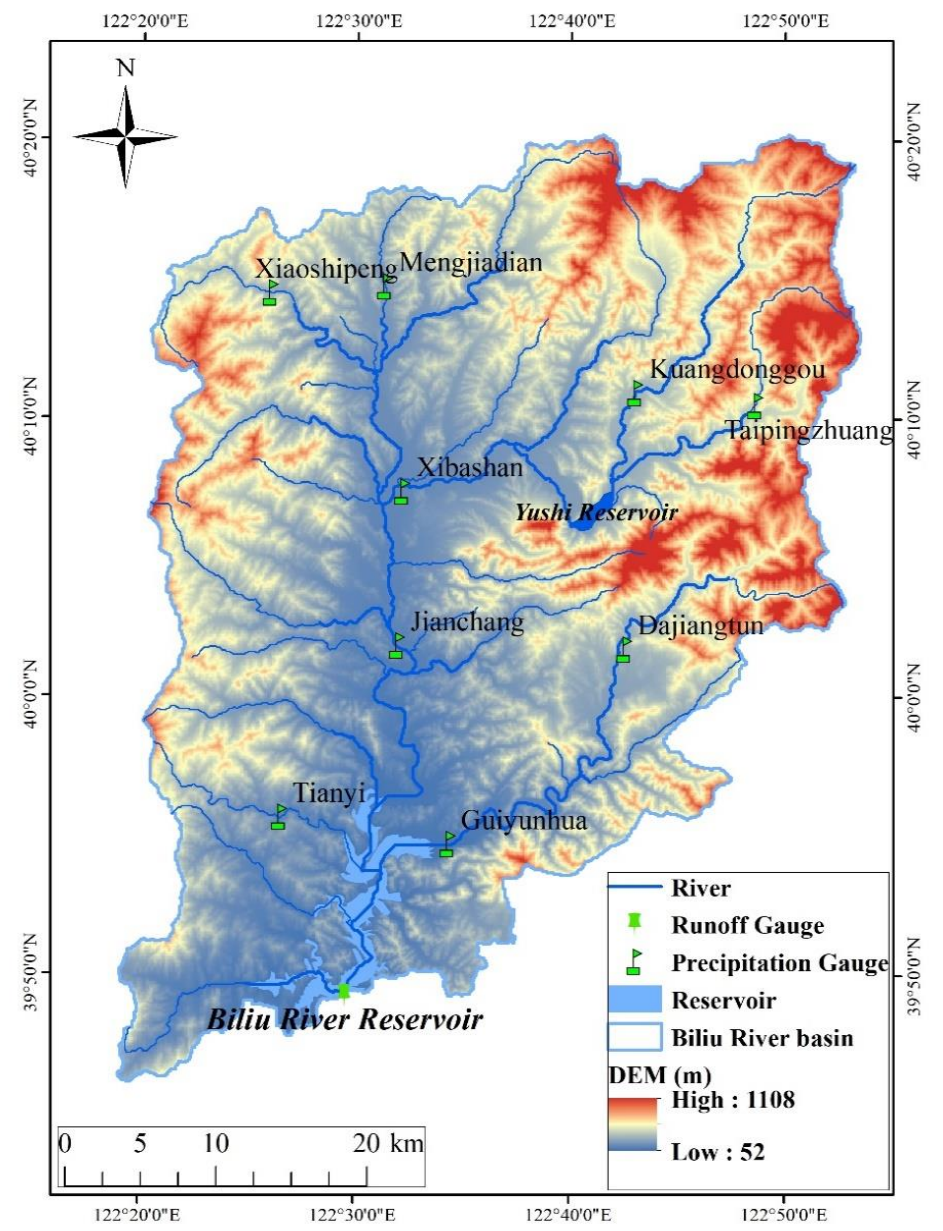

148

149 Fig.2. The location of precipitation gauge, runoff gauge, river, boundaries in Biliu River basin. 


\subsection{Hydrological modeling and parameter uncertainty assessment}

The SWAT 2012 is used to simulate runoff in this study. SWAT is a physically based water-scale model which is widely used in investigating hydrological processes around the world (Wang et al. 2020). The model divided the watershed into hydrologic response units (HRUs), each of these HRUs based on a unique combination of soil, land use and slope characteristics (Nie et al. 2011). Recently, the model has been developed to estimate the climate change impact on hydrological regimes in the predict conditions over long periods of future. The SWAT-CUP software was utilized for calibration and uncertainty assessment of parameters (Abbaspour et al. 2007). SUFI2 algorithm was chosen to calibrate and validate the parameters in the SWAT-CUP (Abbaspour et al. 2004). In order to account for the parameter uncertainty of the model, this manuscript used Latin hypercube sampling (LHS) to generated hydrological model parameter sets. The Nash-Sutcliffe model efficiency $\left(\mathrm{E}_{\mathrm{NS}}\right)$, the average relative error $\left(\mathrm{R}_{\mathrm{e}}\right)$, and the coefficient of determination $\left(\mathrm{R}^{2}\right)$ are used as objective function, which measure the distance between the observations and the simulations. Through sensitive analysis of the calibration process, 11 hydrological input parameters have been generated. The initial iteration of LHS derived 1000 simulations, for all initial parameter sets, the best 100 parameter sets were selected by the condition as $\mathrm{E}_{\mathrm{NS}}$ above 0.9 , $\mathrm{R}^{2}$ above 0.9 and $|\mathrm{Re}|$ below 10 .

\subsection{Climate change scenario and downscaling method}

The CMIP5 have provide future climate database and widely around the world (Kujawa et al. 2020; Zhu et al. 2018; Shi et al. 2020). Six GCMs from CMIP5 were selected to represent the under 2050s and 2080s. al. 2010), this manuscript adopts Morphing approach to remove biased from the original GCMs climate projections, this method involves a shift, a linear stretch (scaling factor), and a 
temperature are calculated by Morphing and shows acceptable performance in the study watersheds more details of the downscaling process were shown in Zhu et al. (2018).

\subsection{The internal variability estimate method}

The internal uncertainty is expected to present the natural viability of the regional climate at decadal multi-decadal time scale in the simulation chains (Lafaysse et al. 2014). In order to investigate the internal variability of the hydrological variables, the external component need be subtracted from variable series, and then the fluctuations of the variable series can be regarded as the internal variability (Frankcombe et al. 2015). The standard deviation of the ensemble variable or the residual to quantify the internal variability is the robust method has been applied in many previous publications (Yu et al. 2020; Maher et al. 2020; Evin et al. 2020; Hingray et al. 2020; Thompson et al. 2015; Lafaysse et al. 2014).

Generally, the internal variability is quantified by the "detrend" and "differenced" method, which can separate the internal variability and external forcing (Frankcombe et al. 2015; Kim et al. 2018). In these two methods, firstly, the external forcing can be estimate, secondly, the external forcing is subtracted from the hydrological variable series, and then the fluctuations of the variables are regarded as internal variability. (Frankcombe et al. 2015; Zhang and Huang 2013)

\subsection{Uncertainty evaluation and decomposition}

For a simulated chain as GCMs-ES, the total uncertainty comes from GCMs, external variability (emission scenarios) and internal variability.

(1) The different components of the total uncertainty

The hydrological projections can be decomposed by hydrological variability and internal variability (Evin et al. 2019; Hingray et al. 2019). The raw hydrological projections $Y_{i, j}$ under climate change can be express as Eq. (1).

$$
Y_{i, j}=\varphi_{i, j}+\eta_{i, j}
$$

Where $\varphi_{\mathrm{i}, \mathrm{j}}$ is the hydrological variability under the hydrological simulation chain; $\eta_{\mathrm{i}, \mathrm{j}}$ is the residual variance of the climate variability for the given hydrological simulation chain, it can also be express as internal variability.

The hydrological variability $\varphi_{\mathrm{i}, \mathrm{j}}$ of any simulation chain can be defined as Eq. (2):

$$
\varphi_{i, j}=\mu+\alpha_{h}+\beta_{k}+\gamma_{l}+\xi_{h, k, l}
$$


hydrological model parameters; $\beta_{\mathrm{k}}$ is the effect contribute by GCMs; $\gamma_{1}$ is the effect contribute emission scenarios;

$\xi_{\mathrm{h}, \mathrm{k}, \mathrm{l}}$ is the interaction terms of the model.

On the base of the above expression of the raw output from simulate chains, the overall variance of the runoff projections $\operatorname{Var}\left[Y_{h, k, l}\right\rfloor$ as flowing:

$$
\operatorname{Var}\left\lfloor Y_{h, k, l}\right\rfloor=\operatorname{Var}\left\lfloor\varphi_{h, k, l}\right\rfloor+\operatorname{Var}\left\lfloor\eta_{h, j, k}\right\rfloor
$$

Where $\left.\operatorname{Var} \mid \varphi_{h, k, l}\right\rfloor$ is the uncertainty in the hydrological variable under climate change, $\operatorname{Var}\left[\eta_{h, j, k}\right\rfloor$ is the

uncertainty of internal variability of hydrological variable.

$$
\left.\operatorname{Var}\left\lfloor\varphi_{h, j, k}\right\rfloor=\operatorname{Var}\left[\alpha_{h}\right]+\operatorname{Var} \mid \beta_{j}\right\rfloor+\operatorname{Var}\left[\gamma_{k}\right]+\operatorname{Var}\left[\xi_{h, j, k}\right\rfloor
$$

Where $\operatorname{Var}\left[\alpha_{h}\right]$ is the variance of SWAT model parameters effects; $\operatorname{Var}\left[\beta_{j}\right]$ is the variance of GCMs model effect; $\operatorname{Var}\left[\gamma_{k}\right]$ is the variance of the emission scenarios; $\operatorname{Var}\left[\xi_{h, j, k}\right\rfloor$ is the variance of the interaction effects.

(2) The uncertainty quantified and decomposition

This manuscript constructs a three-way ANOVA framework to decomposition the different uncertainties contribution, this technology has ability to partition the total observed variance into different sources, and then quantify the contribution of different sources to total variance (Wang et al. 2018; Aryal et al. 2017).

It based on a biased variance estimator that underestimates the variance when the sample size is small. In order to diminish the bias effects caused by the different number of levels of the uncertainty factors, Bosshard et al. (2013) proposed a subsampling method was applied in this manuscript. This subsampling technology selected two samples from the large sample sets, and then a new sample can be generated for ANOVA. This study selects two SWAT parameters sets out of the 100 sets, the superscript $\mathrm{j}$ was replaced by $\mathbf{g}(\mathrm{h}$, $\mathrm{i})$, which is $2 \times 4950$ matrix as following: expressed as Eq. (6). It is composed by the mean effects of SWAT model parameters $\left(\alpha_{\mathrm{h}}\right)$, GCMs model $\left(\beta_{\mathrm{k}}\right)$, emission scenarios $\left(\gamma_{1}\right)$, internal variability $\left(\eta_{\mathrm{h}, \mathrm{j}, \mathrm{l}}\right)$ and interaction effects $\left(\xi_{\mathrm{h}, \mathrm{j}, 1}\right)$. The mean effects can be computer as the deviation of each factors mean value and the global mean 


$$
M^{g(h, j), k, l}-M^{g(-, j),-,-}=\alpha_{h}+\beta_{j}+\gamma_{l}+\eta_{h, j, l}+\xi_{h, j, l}
$$

237 In the ANOVA model, the total variance of the hydrological variable $M^{g(h, j), k, l}$ is expressed as the total sum of squares (SST), and it can decompose into individual variance of each effect:

239

$$
S S T=S S A+S S B+S S C+S S I V+S S I
$$

Where SSA, SSB, SSC is the uncertainty contribution of SWAT model parameters, GCMs, emission scenarios respectively, SSIV is the internal variability and SSI is the contribution of the interaction effects between SWAT model parameters, GCMs and emission scenarios.

By this approach, the intercomparisons among the uncertainty contribution of SWAT model parameter, GCMs, emission scenarios, internal variability and the interaction effects are not affected by the different sampling number.

\section{Results}

\section{1 hydrological model parameters calibrated and uncertainty}

The SWAT model is constructed based on the historical daily meteorological data and spatial geographic data of the study basin. Before being used to predict the future runoff, the hydrological model parameters need to be calibrated and validated. This study divided the calibration period (1982 1996) and validation period (1997 2011) based on the precipitation and runoff changing trends. The simulated data from the SWAT was compared with the historical observed data to ensure its reliability. Three metrics $\mathrm{E}_{\mathrm{NS}}, \mathrm{R}_{\mathrm{e}}$, and $\mathrm{R}^{2}$ are been used to estimate the model performance during calibrated and validated period. More details about the calibration and validation were introduced in (Zhu et al. 2018). The SUFI2 method is used to calibrate the parameters for the 1982-2011 period runoff in study area. The parameters setting was shown in

\section{Table 2.}


Table 2 The selected SWAT model parameters

\begin{tabular}{llcc}
\hline Parameter & \multicolumn{1}{c}{ Definition } & Min & Max \\
\hline CN2 & Initial SCS runoff curve number for moisture condition & 0.75 & 1.25 \\
SURLAG & Surface runoff lag coefficient & 1.00 & 23.98 \\
LAT_TTIME & Lateral flow converge coefficient & 0.01 & 179.92 \\
ESCO & Soil evaporation compensation factor & 0.01 & 1.00 \\
GW_DELAY & The delay time & 0.37 & 500.00 \\
ALPHA_BF & Baseflow alpha factors (days) & 0.00 & 1.00 \\
& Threshold depth of water in the shallow aquifer required for return & & \\
GWQMN & flow to occur & 0.41 & 499.72 \\
SFTMP & Snowfall temperature & -5.00 & 5.00 \\
SMFMX & Melt factor for snow & 1.50 & 8.00 \\
TIMP & Snowmelt temperature lag factor & 0.01 & 1.00 \\
\hline
\end{tabular}

The SUFI2 is used as a parameter uncertainty estimate method for reference period in the study basin. For final ensemble of the 100 parameter sets generate by the LHS, and then these parameter sets are put in the SWAT model to generate 100 behavioral simulations which are performance in Fig. 3 with the help of box plots. Each box represents 100 behavioral simulations which outputs by the calibrated SWAT model. The length of the box plots denotes the runoff changes range from 100 simulations corresponding to one specific month. The differences between two boxes shows the parameters effect are quite differently for one given month. It can be seen in Fig. 3 that the month runoff variability due to SWAT model parameter sets are relatively larger in June to September. As the flooding season (summer and early autumn) in the watershed, the difficulty of the flood control measures would remarkably increase in future, hence, the contribution of the SWAT model parameter sets need be quantified.

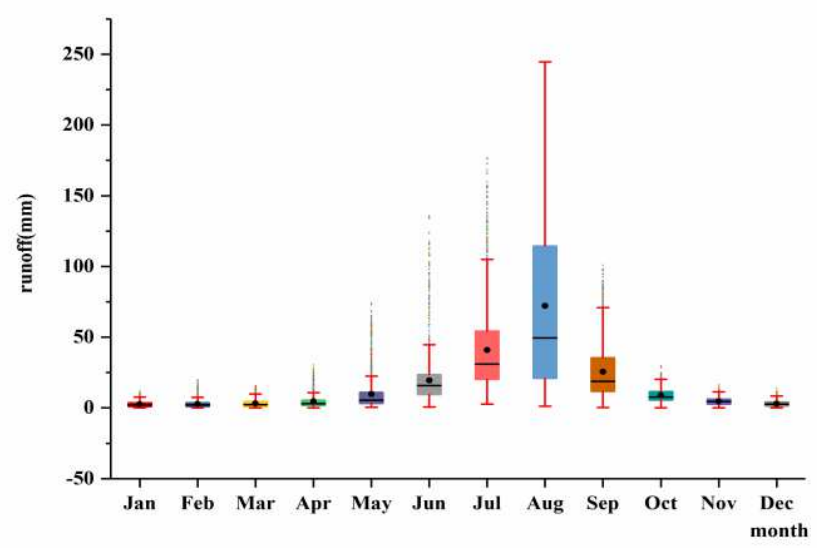

Fig.3. The SWAT model parameters uncertainty of the reference periods. 


\subsubsection{The precipitation projections change under climate change}

The future precipitation projections which were compare with the reference period (1980-2004) and demonstrated in Fig.4. It can be seen that the precipitation projections performance a marked increase trend in 2050s and 2080s. Lots of GCMs-EM simulation chains shows an increased trend, except several model chains shows a decreased trend in winter. It can be noted that the precipitation projections have non-negligible uncertainty in future. This uncertainty of precipitation propagates through the hydrological model and is amplified in the runoff outputs. Hence, the precipitation uncertainty under climate change need be investigated previously.

For the 2050s summer, the precipitation changing interval is from an $54.13 \%$ increase to $-21.2 \%$ decrease, all of the precipitation projections show an increased trend in this period except for CMCC-CM (-5.04\%) and MPI-ESM-MR (-21.20\%) under RCP8.5 scenarios. The uncertainty of precipitation projections is significant in the 2080 s winter, which changes from $-19.79 \%$ to $95.95 \%$. In contrast, the changing rang of spring and autumn are relatively small, among the two future periods, the uncertainty range of spring is from $31.2 \%$ to $-21.27 \%$ in $2050 \mathrm{~s}$, and the range from $1.71 \%$ to $41.18 \%$ in 2080 s autumn. Compared to the other seasons, the change range of spring is smallest in 2080s. Fig.4 displays the precipitation changing ratios has a large changing range for different GCMs in the same emission scenarios as the model uncertainty. And shows different precipitation changing ratios for each GCM in different emission scenarios as the external forcing uncertainty.

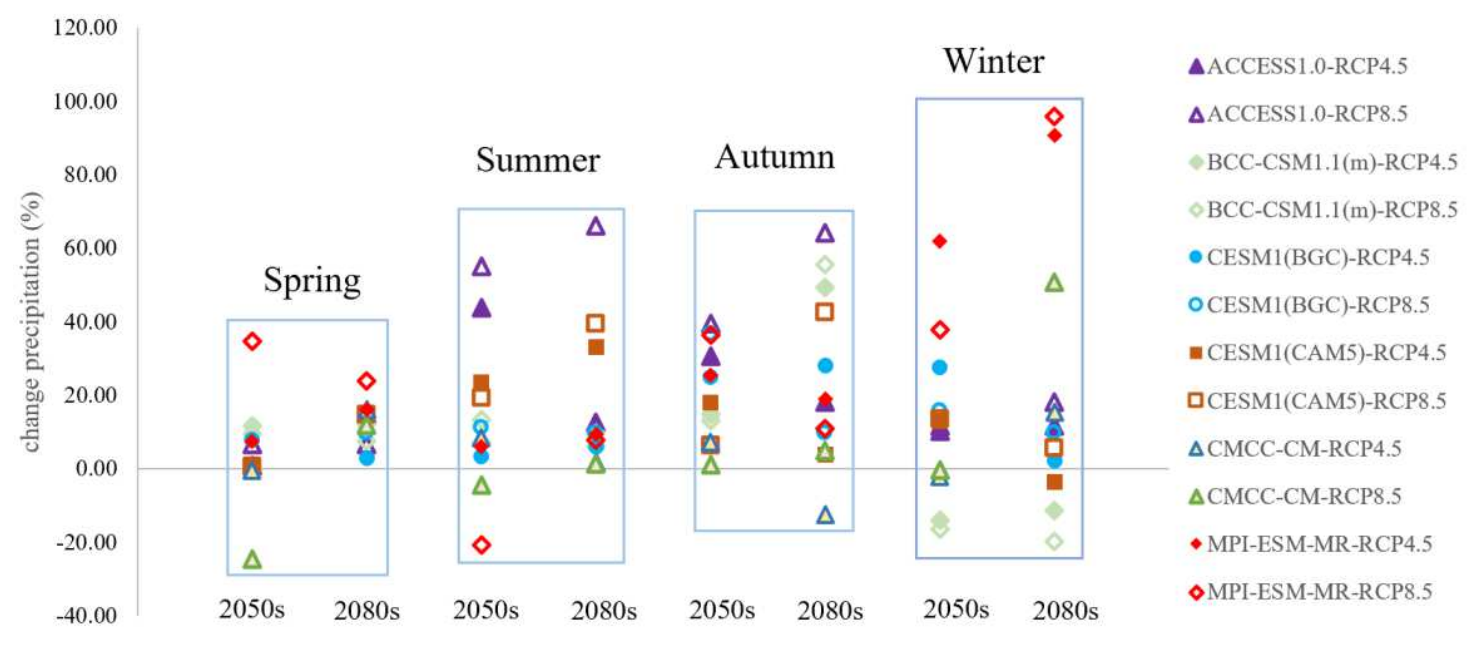




\subsubsection{The temperature projections change under climate change}

304

The box chart of Fig.5a and Fig.5b shows the maximum and minimum temperature ( $\mathrm{T}_{\max }$ and $\mathrm{T}_{\mathrm{min}}$ ) compared to the reference period (1980 2004), the temperature projections show a univocal increased trend for each season among all GCMs-ES simulation chains. Specifically, in the 2050s period, the mean temperature increases of $1.95{ }^{\circ} \mathrm{C}$ under RCP4.5 and $2.73^{\circ} \mathrm{C}$ under RCP8.5, while increase of $2.73{ }^{\circ} \mathrm{C}$ under RCP4.5 and $4.20^{\circ} \mathrm{C}$ under RCP8.5. Moreover, under RCP4.5, the $T_{\max }$ increase range in winter and summer is larger than the other season, the mean $T_{\max }$ in summer increases of $1.84^{\circ} \mathrm{C}$ for $2050 \mathrm{~s}$ and $2.52^{\circ} \mathrm{C}$ for $2080 \mathrm{~s}$, while the mean $\mathrm{T}_{\max }$ in winter increases of $2.17^{\circ} \mathrm{C}$ for $2050 \mathrm{~s}$ and $2.65^{\circ} \mathrm{C}$ for $2080 \mathrm{~s}$.

Similar increasing trends are also shown in $\mathrm{T}_{\min }$ under RCP4.5, the mean $\mathrm{T}_{\min }$ in winter increases of $2.17^{\circ} \mathrm{C}$ for $2050 \mathrm{~s}$ and $2.73^{\circ} \mathrm{C}$ for $2080 \mathrm{~s}$. In addition, under RCP8.5, the greatest increase of mean $\mathrm{T}_{\max }$ is shown in winter, which increase of $3.50^{\circ} \mathrm{C}$ for $2050 \mathrm{~s}$ and $4.50^{\circ} \mathrm{C}$ for 2080s. Again, the mean $\mathrm{T}_{\max }$ also increases significant in summer and autumn under RCP8.5, where mean $\mathrm{T}_{\max }$ increases from $2.61^{\circ} \mathrm{C}$ for 2050 s summer to $4.17^{\circ} \mathrm{C}$ for $2080 \mathrm{~s}$ autumn. There is a similar increasing trend in $\mathrm{T}_{\min }$ under RCP8.5, and the increases of summer, autumn and winter are all above $4.0^{\circ} \mathrm{C}$. In contrast to the increase temperature in two periods of future, it can be found that the uncertainty of $\mathrm{T}_{\max }$ and $\mathrm{T}_{\min }$ are largely determined by GCMs. For instances, the ACCESS1-0 model shows the maximum increases and the CESM1-BGC shows the minimum increase of $T_{\max }$ in 2050s summer, however, the MPI-EMS-MR shows the minimum increase of $\mathrm{T}_{\max }$ in 2080s summer. 

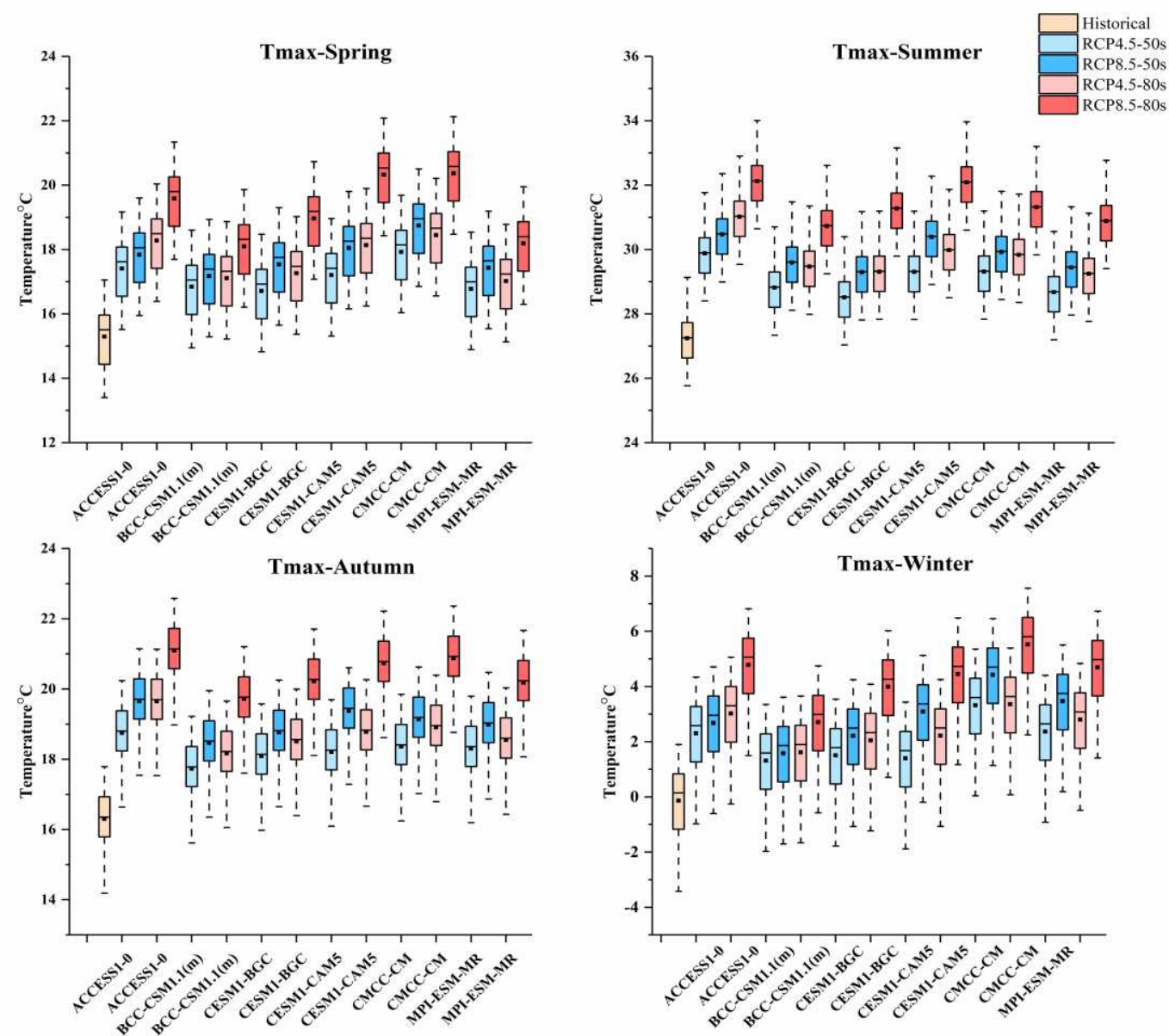

Fig.5a The Tmax in 2050s and 2080s under RCP4.5 and RCP8.5 scenarios based on 6 GCMs compare with reference period (1980-2004). Lower and upper box boundaries indicate the $25^{\text {th }}$ and $75^{\text {th }}$ percentiles, respectively. The black lines and dots inside the box represent the median and mean value, respectively. The lower and upper whiskers indicate the $10^{\text {th }}$ and $90^{\text {th }}$ percentiles, respectively. 

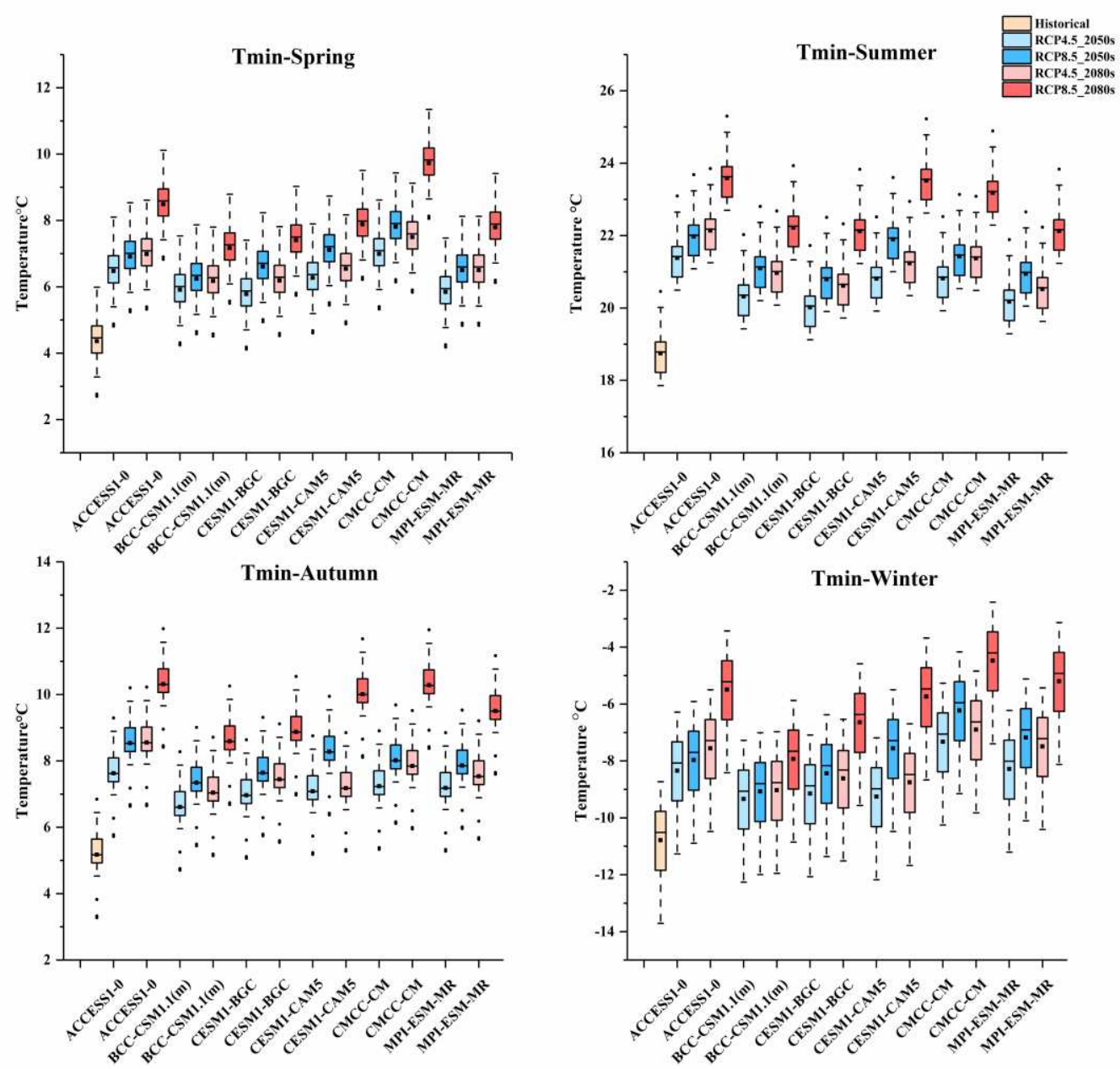

Fig.5b The T-min in 2050s and 2080s under RCP4.5 and RCP8.5 scenarios based on 6 GCMs compare with reference period (1980-2004). Lower and upper box boundaries indicate the $25^{\text {th }}$ and $75^{\text {th }}$ percentiles, respectively. The black lines and dots inside the box represent the median and mean value, respectively. The lower and upper whiskers indicate the $10^{\text {th }}$ and $90^{\text {th }}$ percentiles, respectively.

\subsubsection{The ET projections change under climate change}

The ensemble of 1200 GCMs-SDM-HM simulation chains are established to output 1200 sets ET projections in 2050s and 2080s, the future season ET projections comparing with baseline period shows in Fig.6a and Fig.6b. For RCP4.5 emission scenarios, the season mean ET projections shows an obvious increased trend in summer and winter. However, the autumn mean ET projections demonstrate a relatively smaller increased, some of the models show a decreased trend. Consistent changing trend can be obtained in RCP8.5 emission scenarios, moreover, the ET projections shows a diversity between 2050s and 2080s. 

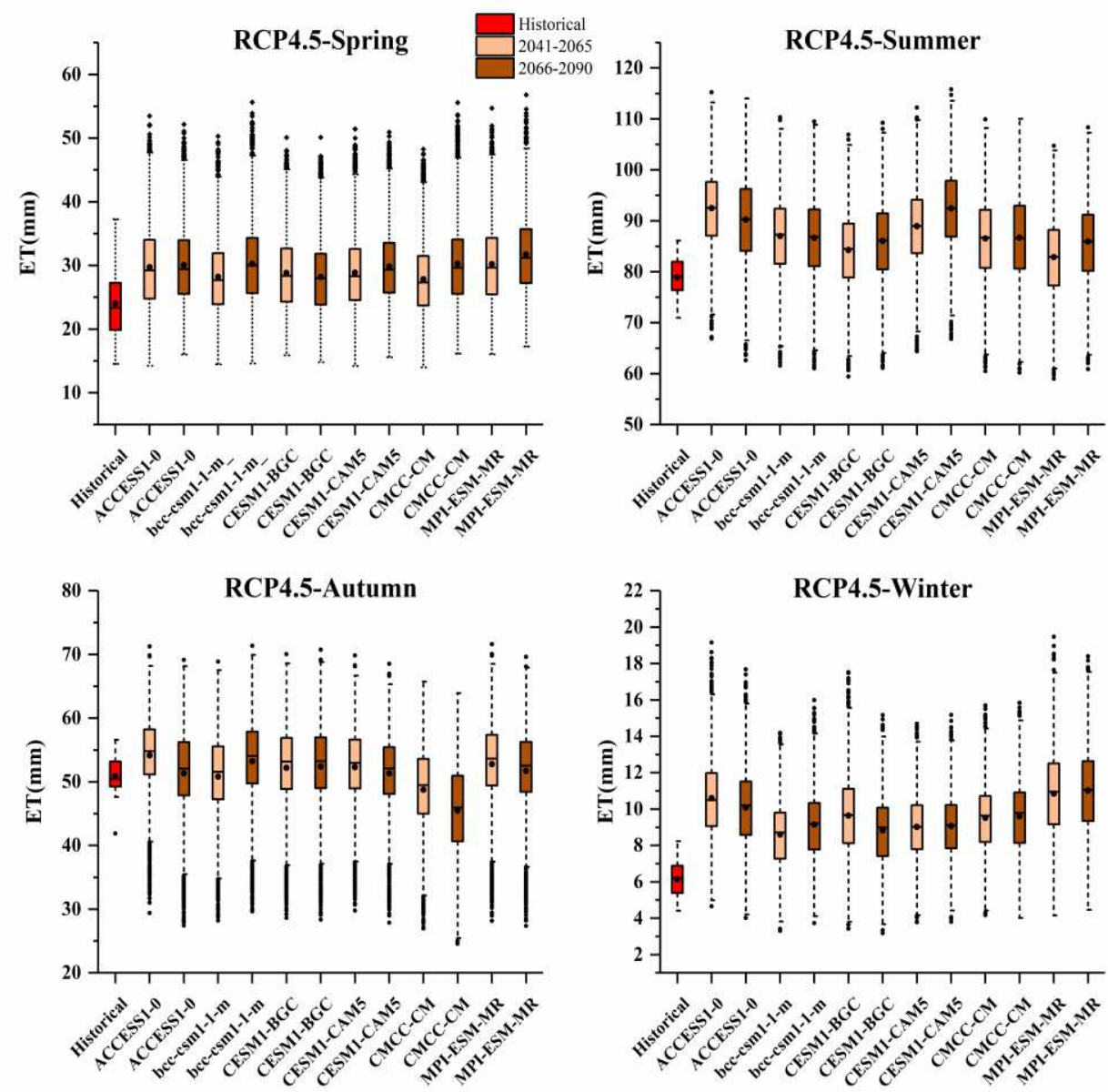

Fig.6a The ET in 2050s and 2080s under RCP4.5 scenarios based on 6 GCMs compare with reference period (1980-2004). Lower and upper box boundaries indicate the $25^{\text {th }}$ and $75^{\text {th }}$ percentiles, respectively. The black lines and dots inside the box represent the median and mean value, respectively. The lower and upper whiskers indicate the $10^{\text {th }}$ and $90^{\text {th }}$ percentiles, respectively. 

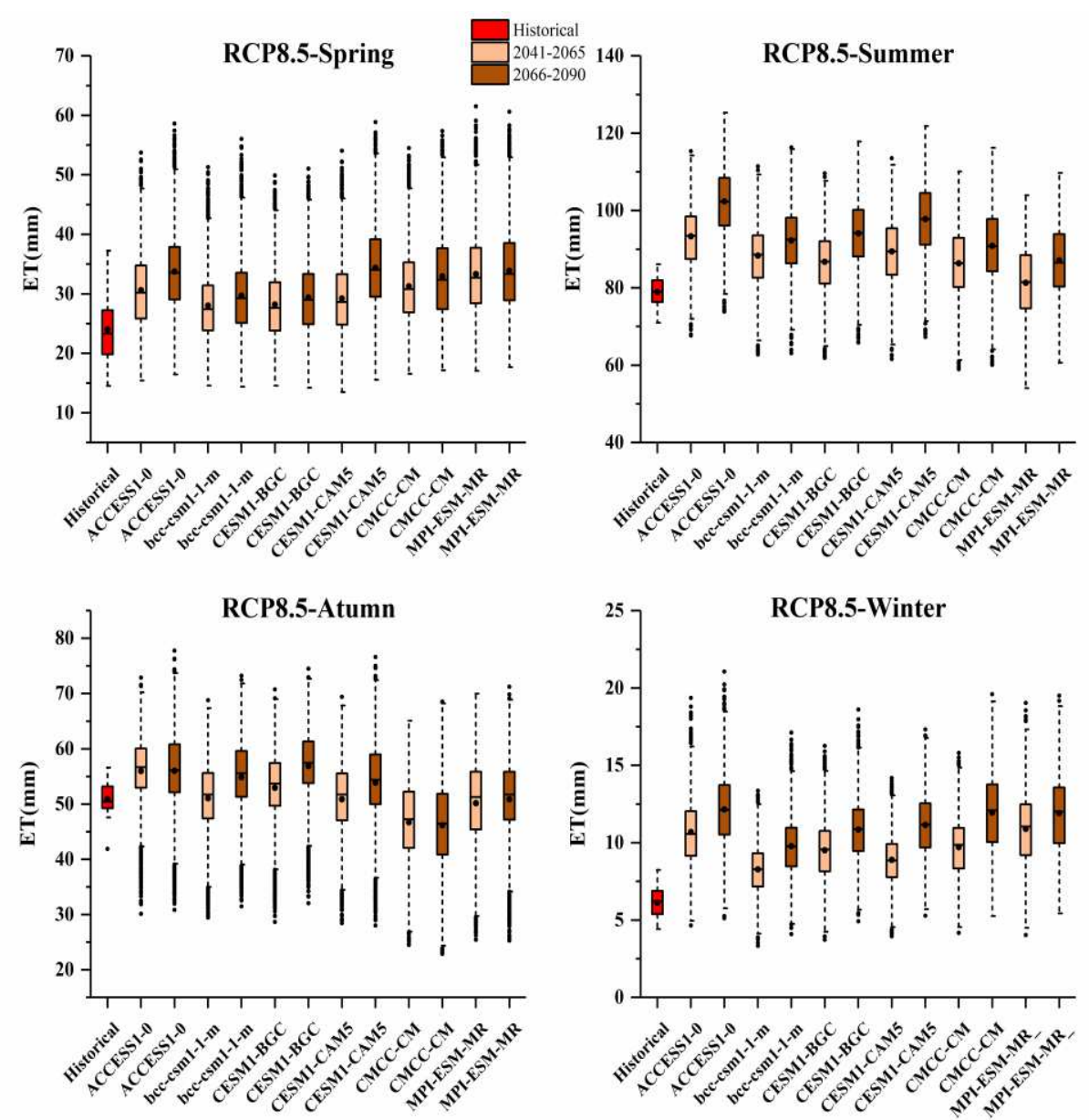

Fig.6b The ET in 2050s and 2080s under RCP8.5 scenarios based on 6 GCMs compare with reference period (1980-2004). Lower and upper box boundaries indicate the $25^{\text {th }}$ and $75^{\text {th }}$ percentiles, respectively. The black lines and dots inside the box represent the median and mean value, respectively. The lower and upper whiskers indicate the $10^{\text {th }}$ and $90^{\text {th }}$ percentiles, respectively.

\subsubsection{The runoff projections change under climate change}

The ensemble of 1200 GCMs-EM-HM simulation chains are established to output 1200 sets runoff projections in 2050s and 2080s. The 1200 simulation chains, which includes six GCMs, two emission scenarios, 100 SWAT model parameter sets. The predicted runoff projections of four seasons in two future periods are compared with the reference period in Fig.7a and Fig.7b, each box and whisker plots for runoff projections are generated from 1200 simulation chains. For 2050s, the runoff projections increase more significant in autumn than the other seasons. In terms of changes in autumn runoff, all projections of runoff show an increased trend in basin, ranging $1.37 \%-66.01 \%$ under RCP4.5 and $-11.99 \%-97.08 \%$ under RCP8.5. The projected of summer 
runoff varies from $-18.41 \%$ to $47.78 \%$, the projects changing show difference among the six

370 GCMs, for instance, ACCESS1-0 projected an increase $47.78 \%$ while CESM1-BGC projects a

371 decrease $-18.41 \%$ under RCP4.5. These differences are more significant under RCP8.5, for

372 example, the ACCESS1-0 projected an increase $70.41 \%$ while the other models all demonstrated a

373 decrease trend. For 2080s, there still exist obvious differences among projections, however, a

374 relatively consistent increasing trend can be found in autumn under RCP4.5 and RCP8.5. In

375 contrast, the runoff projections of summer show a decrease trend among five models ranging from

$376-25.29 \%$ to $-5.21 \%$, except for CESM1-CAM5 model showed an increases trend of $29.37 \%$ under

377 RCP4.5 scenarios. While the summer runoff projections showed increases from $7.93 \%$ to $85.76 \%$

378 and decreases from $-11.6 \%$ to $-29.15 \%$, the decrease trend is smaller than increase trend, thus, a

379 slight increase trend with the mean increase value as $11.95 \%$ can be found in 2080s under RCP8.5.

380 In addition, the runoff projections shown a slight increases trend in autumn and winter both

381 under RCP4.5 and RCP8.5 scenarios, and also shown a small various among different GCMs.

382 

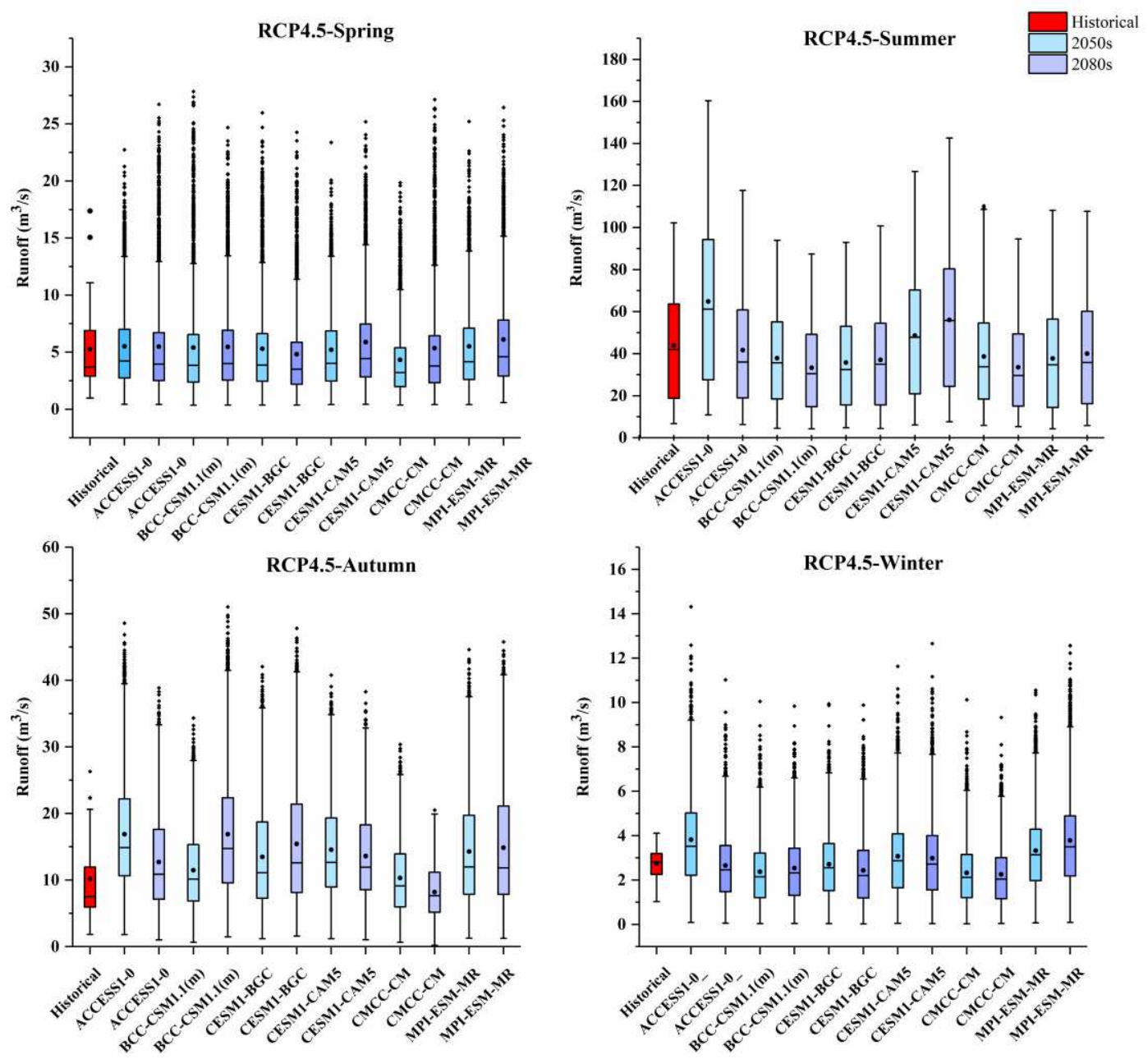

Fig.7a The runoff in 2050s and 2080s under RCP4.5 scenario based on 6 GCMs compare with reference period (1980-2004). Lower and upper box boundaries indicate the $25^{\text {th }}$ and $75^{\text {th }}$ percentiles, respectively. The black lines and dots inside the box represent the median and mean value, respectively. The lower and upper whiskers indicate the $10^{\text {th }}$ and $90^{\text {th }}$ percentiles, respectively. 

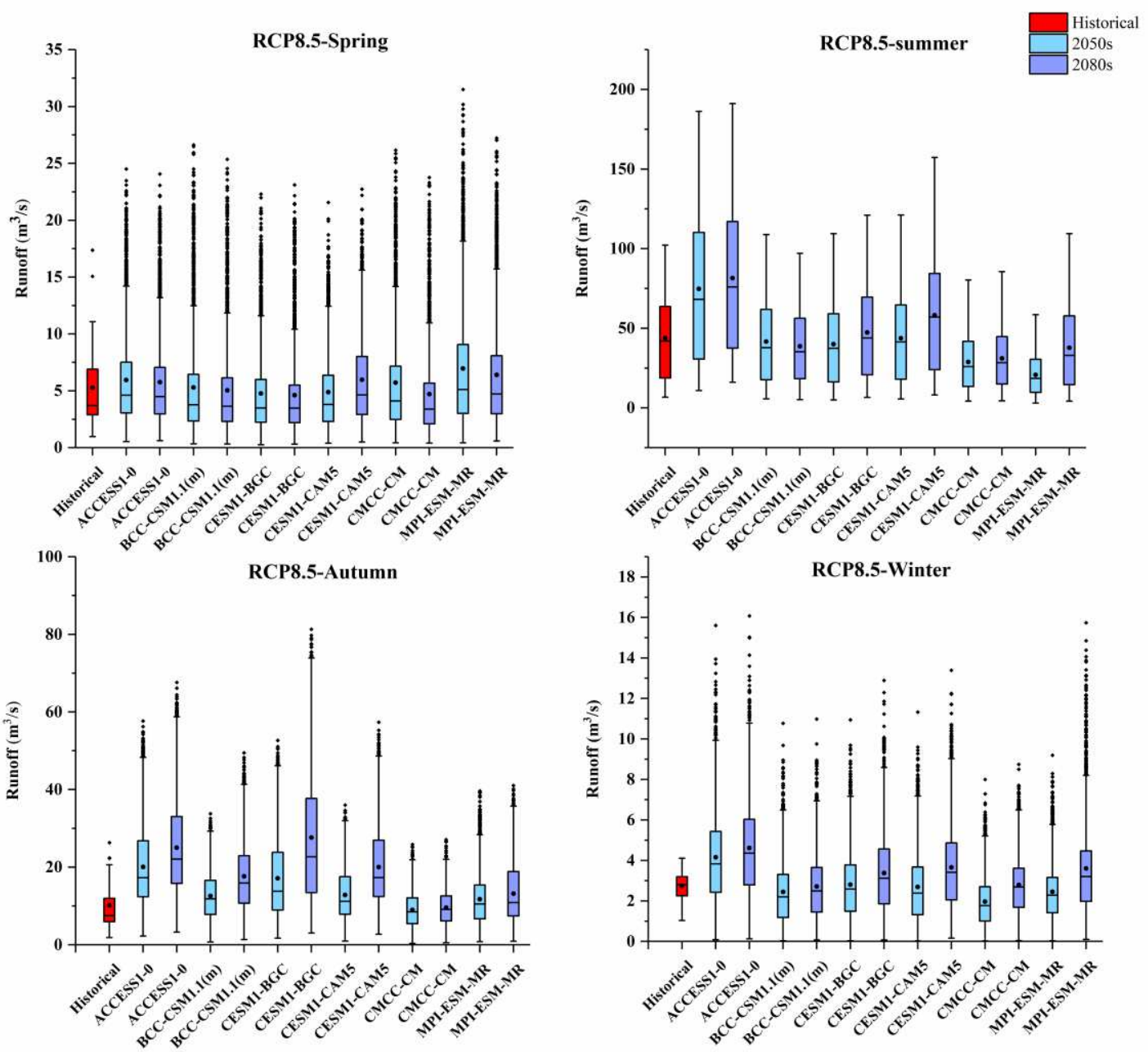

Fig.7b The runoff in 2050s and 2080s under RCP8.5 scenario based on 6 GCMs compare with reference period (1980 2004). Lower and upper box boundaries indicate the $25^{\text {th }}$ and $75^{\text {th }}$ percentiles, respectively. The black lines and dots inside the box represent the median and mean value, respectively. The lower and upper whiskers indicate the $10^{\text {th }}$ and $90^{\text {th }}$ percentiles, respectively.

Furthermore, the box-and-whisker plots show in Fig.7a and Fig.7b, the upper and lower ends represent the highest and lowest runoff, and the change range indicated the uncertainty bound. Compared with the runoff in reference period, the projected runoff reveals a slight increase in mean and median values and wide uncertainty range under RCP4.5 and RCP8.5 scenarios. Accordingly, the runoff projections under RCP8.5 projections demonstrate obvious large uncertainty than RCP4.5 scenarios. Compared with the other seasons, the summer runoff projections showed the largest uncertainty brands under two emission scenarios in future. Observing median values, the summer and autumn projections in 2050s and 2080s show the non-negligible differences, for example, the median values for summer under RCP4.5 scenario 

MPI-ESM-MR, which ranging from $-22.82 \%$ to $-15.04 \%$, in contrast, the median values show an increase from $45.55 \%$ to $13.79 \%$ in projected of ACCESS1 and CESM1-CAM5. In addition, the median values for the spring runoff projections in 2050s under RCP4.5 portray a consistent slight increase from $3.23 \%$ to $12.51 \%$, only CMCC-CM projection show a decrease as $-12 \%$. Overall, the runoff projected by all GCMs showed a large uncertainty in two future periods. Comparing 2050s and 2080s, it can be found that the lower ends become smaller and the upper ends become larger, which indicate that the uncertainty bonds increasing from 2050s to 2080s. In addition, comparing the RCP4.5 and RCP8.5 scenarios, the uncertainty bound of RCP8.5 scenarios are always larger than RCP4.5.

\subsubsection{Impacts of climate factors to runoff change}

After analyzing the changes of precipitation, $\mathrm{T}_{\max }, \mathrm{T}_{\min }, \mathrm{ET}$ and runoff in future, it can be found that the different climate factors may produce different contribution to runoff changing. Hence, it is important to analyze the relationship between the change of runoff and change of climate factors. In order to determine the relationships between them, the multiple linear regression was performed for each model chain using changes of precipitation, $\mathrm{T}_{\max }, \mathrm{T}_{\min }$ and $\mathrm{ET}$ as the independent variables and the runoff as the dependent variables.

The regression coefficients for runoff are shown in Table 3 In general, the increase of precipitation may cause a positive effect on runoff increasing, this trend can be found in all of the models and scenarios and coefficients at the 0.001 significant level. In contrast, the increase of ET projections was negatively related to runoff, and there are seven projections at the 0.001 significant level. In addition, the increase $\mathrm{T}_{\max }$ and $\mathrm{T}_{\min }$ may contribute the increase trend of runoff, however, the coefficients did not pass the significant test even at 0.05 level. Above all, the precipitation and ET has a larger influence in runoff projection in most model chain. From the CIV values of precipitation and ET, the internal variability of precipitation and ET may pay an important role to runoff. Although the runoff changing under climate scenarios have been widely reported in lots of researches. The large uncertainties were observed in the runoff changing, external forcing, model response and internal variability. 
Table 3 The multiple liner regression coefficients for runoff $\left(\mathrm{R} \mathrm{mm} \mathrm{year}{ }^{-1}\right)$ with maximum temperature $\left(\mathrm{T}_{\max }{ }^{\circ} \mathrm{C}\right)$, model $\left(\mathrm{R}=\mathrm{a}_{1} \mathrm{~T}_{\max }+\mathrm{b}_{1} \mathrm{~T}_{\min }+\mathrm{c}_{1} \mathrm{P}+\mathrm{d}_{1} \mathrm{ET}+\mathrm{e}_{1}\right)$. $\mathrm{p}$ 描述显著性水平: ***: $\mathrm{p}<0.001, * *: \mathrm{p}<0.01, *$ : $\mathrm{p}<0.05$.

\begin{tabular}{|c|c|c|c|c|c|c|}
\hline Models & $a_{1}$ & $\mathrm{~b}_{1}$ & $\mathrm{c}_{1}$ & $\mathrm{~d}_{1}$ & $\mathrm{e}_{1}$ & $\mathrm{R}^{2}$ \\
\hline ACCESS1-0_RCP45 & 22.75 & -21.40 & $0.92 * * *$ & $-0.97 * * *$ & $-197.62 * *$ & 0.96 \\
\hline ACCESS1-0_RCP85 & 61.05 & 23.89 & $0.97 * * *$ & -0.86 & -1284.58 & 0.75 \\
\hline BCC-CSM1.1(m)_RCP45 & 20.96 & -15.30 & $0.85 * * *$ & $-0.81 * * *$ & -237.05 & 0.92 \\
\hline BCC-CSM1.1(m)_RCP85 & 17.26 & -13.92 & $0.84 * * *$ & $-0.76^{* *}$ & -205.54 & 0.93 \\
\hline CESM1(BGC)_RCP45 & 28.98 & -25.77 & $0.86 * * *$ & $0.21 * * *$ & -209.88 & 0.93 \\
\hline CESM1(BGC)_RCP85 & 81.42 & -38.46 & $0.99 * * *$ & -0.5 & $-1370.22 * * *$ & 0.86 \\
\hline CESM1(CAM5)_RCP45 & 18.15 & -17.34 & $0.90 * * *$ & -0.93 & -153.06 & 0.96 \\
\hline CESM1(CAM5)_RCP85 & 22.13 & -20.34 & $0.87 * * *$ & $-0.77 * * *$ & -265.73 & 0.96 \\
\hline CMCC-CM_RCP45 & 5.92 & 18.26 & $0.62 * * *$ & -0.53 & -248.50 & 0.75 \\
\hline CMCC-CM_RCP85 & 15.40 & -14.67 & $0.68 * * *$ & $-0.45^{*}$ & -235.24 & 0.87 \\
\hline MPI-ESM-MR_RCP45 & 29.52 & -24.95 & $0.88 * * *$ & $-1.02 * * *$ & -224.86 & 0.94 \\
\hline MPI-ESM-MR_RCP85 & 24.93 & -15.04 & $0.77 * * *$ & $-0.65^{* *}$ & -348.45 & 0.90 \\
\hline
\end{tabular}

\subsection{Evaluation of the uncertainty influence factors of runoff}

\subsubsection{Quantifying the relative contribution of internal variability and external} forcing in individual model realization results from the superposition of CIV and the external forcing. In order to investigate the internal variability of the precipitation trends, six GCMs are forced by the same external forcing, and then the CIV of the precipitation projections had been calculated under two emission scenarios.

Fig.8 showed the CIV values of precipitation, $\mathrm{T}_{\max }, \mathrm{T}_{\min }$, ET, precipitation and runoff projections. From the CIV values of precipitation, the CIV values are higher in June to September than the other month and the lowest values appeared in December and February. The large diversity across the individual members demonstrated the important role of internal variability in June to September precipitation projection. The internal variability plays an important role in rainy season. Compared with precipitation projections, the CIV values of $T_{\max }$ and $T_{\min }$ are relatively smaller in rainy season than the other month. For ET projections, it can be obtained that the CIV values are large in May to September, which mean that the internal variability plays an important role in ET trends in this period. The CIV values of runoff demonstrate that the internal variability 
is higher in rainy season than the other seasons.

From the CIV values of runoff projections under RCP4.5 and RCP8.5 emission scenarios, it can be found that the CIV values of rainy season are larger than the other seasons, and the maximum CIV value of the runoff projections appeared in August. Hence, the internal variability has an important role in rainy season. variability of precipitation and runoff showed obvious increased in rainy season. On consideration of the summer runoff has significantly influence on the water resources management and flood control, hence, the uncertainty of runoff projections and the contribution of different uncertainty sources need be special investigated.
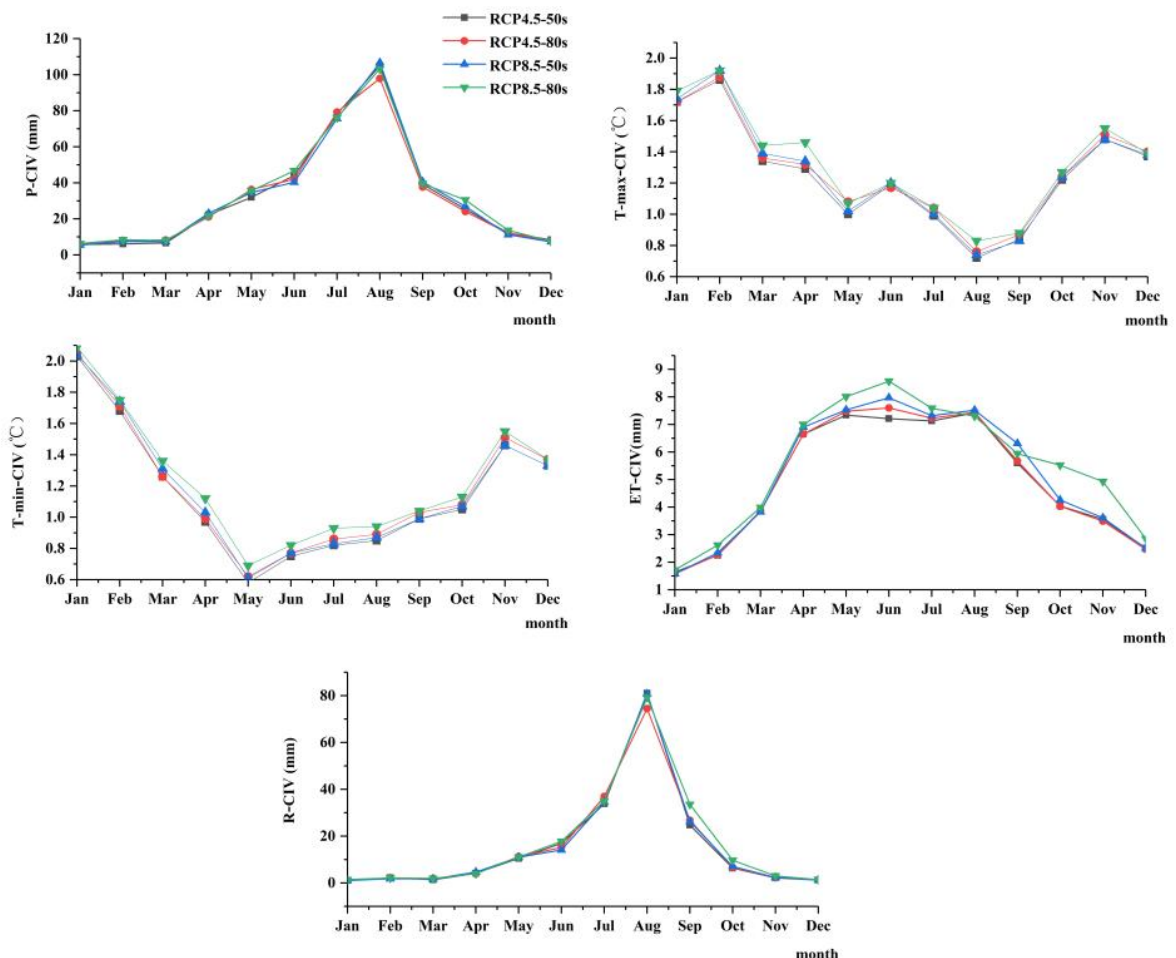

465

Fig.8. The CIV values of climate-hydrological projections

The SNR is defined as the absolute value of ensemble mean divided by the CIV, which can measure the relative contribution of external forcing and internal variability. The SNR values of precipitation, temperature, ET and runoff are showed in Fig.9. This metrics convey useful information about the magnitudes of the forced and internally generated components of climate projections under future climate change. It can be seen from the Fig.9 that the SNR values of 
precipitation and runoff are relatively smaller than the other climate projections.

The SNR values of $\mathrm{T}_{\max }$ and $\mathrm{T}_{\min }$ demonstrate a relatively higher values in May to October, it worth noting that the temporal pattern of the SNR is mainly determined by the internal variability pattern in November to March and by a mainly combination of forced response in April and October. The SNR of ET is higher in June to October than the other month in 2050s period, and it is relatively stable in 2080s period. Hence, the external forcing is the mainly components of ET projections changing. In addition, the SNR of runoff is relatively small which like precipitation. An important result is that the external forcing contributed a considerable higher component in temperature and ET changing than precipitation and runoff, and the SNR exhibits higher values in June to September than the other models in both two emission scenarios and future periods.
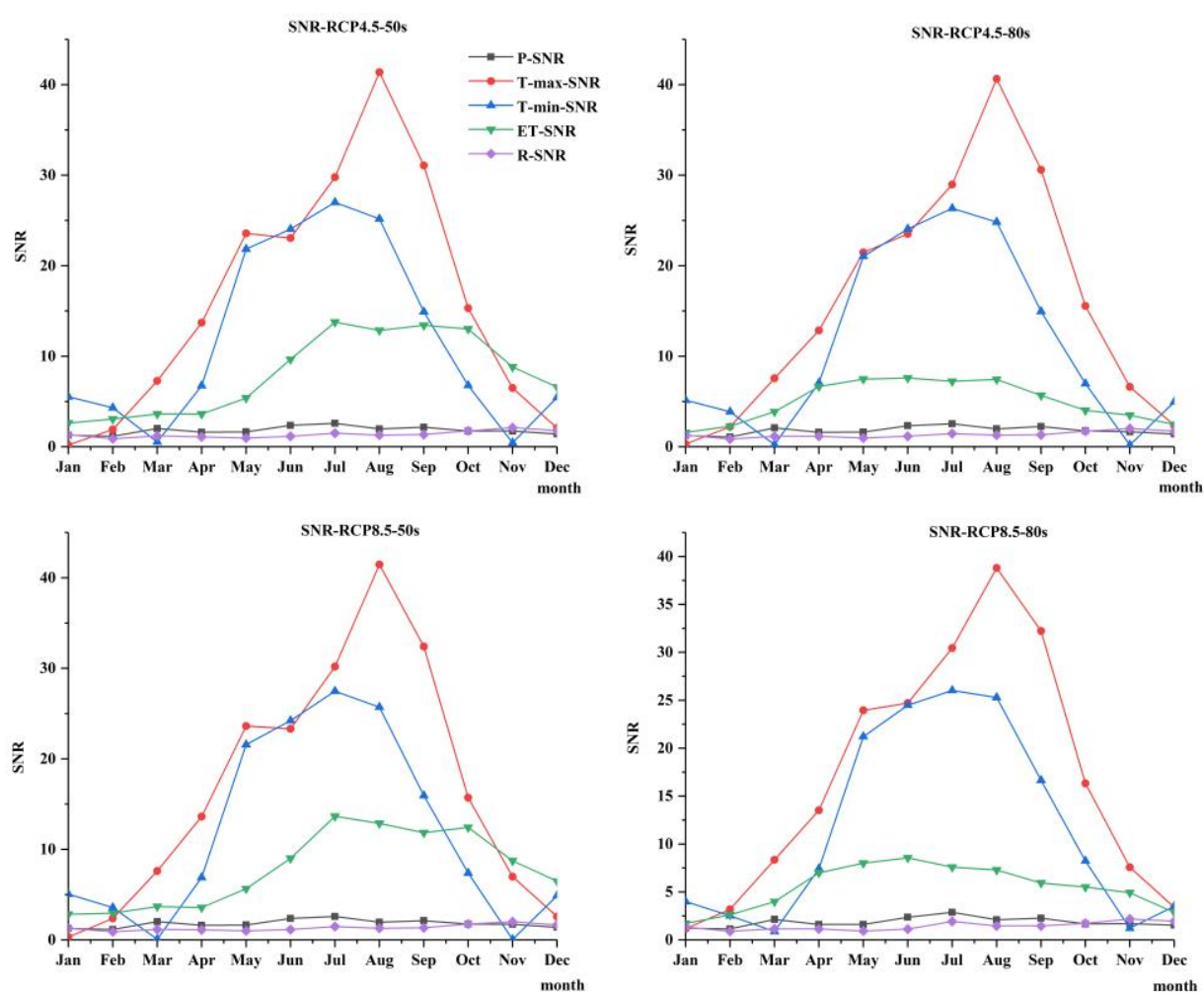

Fig.9 The SNR values of climate-hydrological projections

\subsubsection{Contribution analysis of uncertainty sources}

As mentioned previously, the uncertainty sources of GCMs-EM involve external forcing, model response, and internal variability. From the contribution of the external forcing and internal variability, it can be observed that the external forcing plays an important role in temperature and 
ET changing. In compatible, the SNR values of the runoff are relatively small, with values mostly around 1 in both scenarios and future periods. However, the SNR values can't able to quantify the internal variability and external forcing contribution to total uncertainty.

The ANOVA method is used to quantified the uncertainty contribution of different sources of uncertainty in 2050s and 2080s.
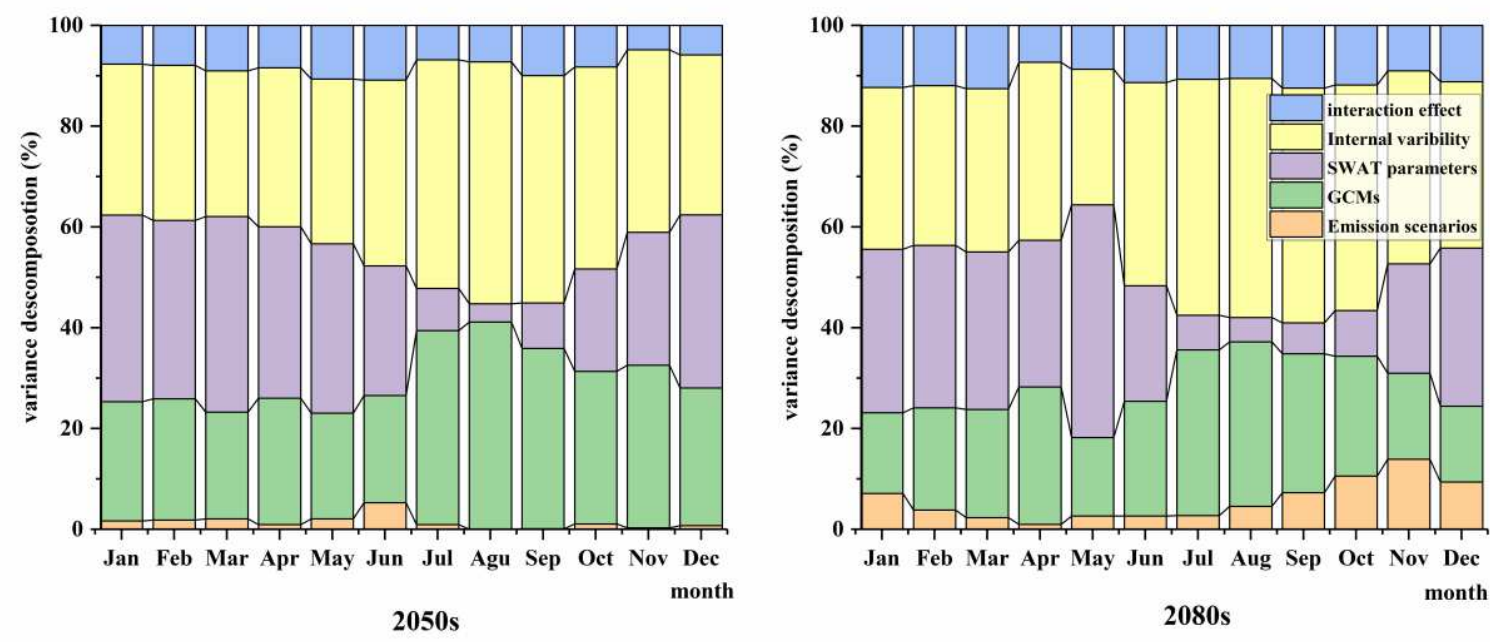

Fig.10 The contribution of uncertainty sources to the runoff in 2050s and 2080s period.

The contribution of uncertainty sources showed in Fig.10. It is noteworthy that the effect of internal variability is non-negligible, which is exceeded the contribution due to the GCMs. It contributes $29 \%-48 \%$ and $31.4 \%-47.4 \%$ of the total variance in 2050 s and 2080 s, respectively. The biggest contribution embodies in September in two future periods, which is late flooding season in watershed. The second significant uncertainty contributor is GCMs, which account for $21 \%-41 \%$ and $15 \%-33 \%$ in 2050s and 2080s, and the biggest uncertainty is in September (2050s) and August (2080s) respectively. For the SWAT model parameter sets, the contribution accounts for $4 \%-39 \%$ and $4.8 \%-32.4 \%$ in 2050 s and 2080 s, respectively. Compared with the previous two uncertainty sources, the SWAT model parameters main effect the Spring (March to May) and Winter (December to February) runoff projections. The interaction term contribution to the runoff projection explaining approximately $8 \%-11 \%$ and $7 \%-12 \%$ throughout the 2050 s and 2080 s periods, respectively. The contribution of emission scenarios is relatively small, which bellows 5\% and $10.5 \%$ in $2050 \mathrm{~s}$ and 2080 s, respectively. 
511 internal variability to the overall uncertainty, and the dominant sources of uncertainty are GCMs

512 and SWAT model parameters. The results also show that the internal variability and GCMs mainly

513 effect the runoff in June and October, which contained the entire flood season in Northeastern of

514 China.

515

516

517

\section{Discussion}

\subsection{Climate-hydrological projections changes}

This study estimated climate-hydrological projections changes under climate change impacts in a respective watershed in Northeastern China. Compared with the reference period, the temperature and precipitation projections performance an increased trend in two future periods, and this increased trend is more significant under RCP8.5 emission scenarios and later future period as 2080s. This finding is consistence with some pervious publications, Wang et al. (2020) found that the response of hydrological extreme events to climate changing shows much higher in 2070-2099 under RCP8.5 scenarios. The ET projections shows obvious increase trend in summer and winter, and a relatively small increase trend in autumn, although the two emission scenarios have a similar changing trend, a diversity changing can also be found between different models under RCP8.5 periods. For the runoff projections, this study found that there exist a relatively consist increased trend in autumn than the other seasons in two future periods. From the multiple linear regression analysis of runoff, the precipitation has a significant positive effect on runoff, and ET shows a relatively small negative effect on runoff. Hence, the increase precipitation and relatively small increase ET may due to a relatively obvious increased in autumn.

However, the projected of runoff in future also demonstrated an obvious diversity in future, especially in Summer and Autumn. On consideration of the two seasons contained the flood season of the study watershed, the uncertainty of the GCMs-EM-HM simulation chain need be estimate step to step.

\subsection{Internal variability and external forcing}

From climate-hydrological prediction results, it can be found an obvious uncertainty of each simulation chain. As above mentioned, the internal variability and external forcing influence on the climate projections is investigated by CIV and SNR two indicates. The GCMs-EM-HM chains 
have been operated for six GCMs under a same emission scenario, and then the CIV and SNR values of the precipitation and temperature projections have been computed for each GCMs-EM-HM chain.

The findings indicated that the CIV values of precipitation, ET and runoff are large in rainy season, which consistence contained June and September, the results showed that the internal variability pay an important role in theses climate projections. The SNR values of precipitation and runoff are stable among 12 months, it is difficult to determine which is the important influence source of climate-hydrological projections by the SNR values. Considering the June to September contains the entirely flood season in research watershed, the annual internal variability and external forcing uncertainty contribution of runoff projections need be investigated particularly.

\subsection{Uncertainty assessment}

The ANOVA framework was constructed to quantify the uncertainty sources contribute to the overall uncertainty, furthermore, in considering the substantial effects of internal variability on the uncertainty of runoff projections, the uncertainty contribution of internal variability has been considered to ensure the comprehensive of uncertainty assessment.

From the results from ANOVA framework, the internal variability and GCMs are the main contributor in runoff projections in rainy season. In addition, the third important effect term is SWAT model parameter sets, it plays important role in overall uncertainty in January to May and October to December.

These findings indicate that the internal variability is the important uncertainty sources among the different sources chosen by this study, which agree with the findings of some previous publications (Lafaysse et al. 2014; Hingray et al. 2019). Meanwhile, the runoff projections are significantly impact by the choices of GCMs, this point also has been found in many studies (Kujawa et al. 2020), for instance, Zhang et al. (2021) found the disparity between different GCMs may mainly impacted the climate change researches, and the increased sample sized of GCMs may conduct a complete uncertainty assessment. As an important tool for runoff simulation and prediction, the hydrological model is a non-negligible uncertainty contributor of overall uncertainty, among the uncertainty derive form the hydrological model, the model parameters obtained more attention (Keller et al. 2019; Vaghefi et al. 2019; Nerantzaki et al. 2020). Moreover, 
the contribution of and interaction effect are relatively small compared with the other uncertainty sources, these findings consist with some previous researches (Bosshard et al. 2013; Qi et al. 2016; Vaghef et al. 2019).

The quantifying of internal viability has been demonstrated in several previous studies (Lafaysse et al. 2014; Evin et al. 2019; Hingray et al. 2019), however, most of the studies focused on decomposition the internal uncertainty of climate system through the GCMs-EM simulation chains (Doi and Kim. 2020; Yu et al. 2020; Maher et al. 2020; Hawkins and Sutton. 2011). Moreover, this study indicates that the internal variability, GCMs model, emission scenarios, hydrological model parameters and interaction effects need be quantified entirely. Because of the annual distribution contribution of different sources are the important information of uncertainty analysis. The contribution of uncertainty sources in each month can be found in the uncertainty quantified results straightforward.

On consideration of the internal variability may propagate in the GCMs-EM-HM simulation chain and effect the runoff uncertainty. Internal variability and external forcing of precipitation, temperature and ET can also provide some useful information to runoff uncertainty analysis. For rainy season, the internal variability and GCMs are the dominant uncertainty in runoff. On the base of multiple linear regression, the precipitation and ET has significantly influence on runoff, and their uncertainty can also influence on runoff uncertainty. From the CIV and SNR values of climate projections, it can be found that the internal variability of precipitation and ET are large in rainy season. Hence, the internal variability of precipitation and ET may affect runoff to some extent. Above all, the internal variability obvious role of the in shaping overall uncertainty, and some of the uncertainty source of runoff projections can be trace bake to precipitation and ET etc.

\section{Conclusion}

An ensemble of GCMs-EM-HMs simulation chains were used in this study to estimate the climate-hydrological projections response to the climate change. Subsequently, the details of different sources of uncertainty are essential for the runoff prediction and to identify the fundamental uncertainty source is meaningful to reduce existing uncertainties in future. The main conclusions of this study can be summarized as flowing:

(1) Based this study analysis of future climate conditions for the Biliu River basin, it can be 
found that an increase in seasonal mean temperature for both emission scenarios, with greatest increase in summer and autumn. In term of precipitation, it indicates an increased trend in summer, autumn and winter and a relatively larger uncertainty in summer and winter. Results based on the SWAT modeling indicated that the ET shows a slight increase in summer and winter, and the runoff projections trend a diversity changing trend in future, especially in summer and autumn. Large uncertainty brings difficult to the water resources and flood control management to propose the adaptation strategy under climate change.

(2) By elucidating the impact of climate internal variability of runoff projections, this study

605

606

607

608

609

610

611

612

613

614 analysis the internal variability and external forcing of climate projections and find out the important influence factor of runoff projections. In term of precipitation and ET, the internal variability is larger in June to September, and the SNR values also shows the internal variability and external forcing are both important influence factors to runoff. Combining with the internal variability and GCMs are the dominate uncertainty contributors in June to September. It is worth noting that the internal variability can propagate in the GCMs-EM-HMs simulation chains, and the internal variability of runoff projections is remarkable in flood season of study watershed in future. As the rain season in the study basin, some water resources adaptation measures need be planned to alleviate the climate change influence, especially in high emission scenarios (RCP8.5) and far future (2080s).

(3) This study found GCMs, internal variability and SWAT model parameters are the mainly uncertainty contributor of runoff. In addition, the SWAT model parameters uncertainty significantly effects runoff projections in spring and winter, thus the calibration of sown melt parameters needs more attention. The influence of external forcing is smaller in GCMs-EM-HMs than GCMs-EM, because the uncertainty sources increased and the hydrological simulation process bring more uncertainty to runoff.

The findings of this study indicate that the uncertainty of climate-hydrological system is noticeable in future, these kinds of uncertainties may extremely influence the stakeholders and local water resources government to provide correct hydrological regulation and flood control measures. This study also reveal that the internal variability is non-negligible in predicting climate-hydrological projections, which is worth more research in future. 


\section{Funding Statement}

This study was sponsored by the Natural Science Foundation of Shanxi Province, China. Grant No.201901D111060. (Xueping Zhu)

This study was sponsored by the Open Research Fund of State Key Laboratory of Simulation and Regulation of Water Cycle in River Basin, China Institute of Water Resources and Hydropower Research, Grant NO. IWHR-SKL-202103. (Wenjun Cai)

\section{Conflicts of interest/Competing interests}

The authors declare that they have no known competing financial interests or personal relationships that could have appeared to influence the work reported in this paper.

\section{Author's Contribution}

Conceptualization, Xuehua Zhao and Yongbo Zhang; Methodology, Wenjun Cai and Xueping Zhu; Formal Analysis, Wenjun Cai and Xueping Zhu; Writing Original Draft Preparation Wenjun Cai and Xueping Zhu; Writing-Review \& Editing, Wenjun Cai and Xueping Zhu; Funding Acquisition, Wenjun Cai and Xueping Zhu.

\section{Availability of data and material}

The climate data in 1901-2099 for RCP4.5 and RCP8.5 were downloaded from the National Climate Center (http://ncc.cma.gov.cn). The long-term experiment data of 1850-2100 for the chosen six climate models in CMIP5 were downloaded from the Program for Climate Model Diagnosis and Itercomparison (PCMDI, http://pcmdi3.llnl.gov/esgcet/). Yearly and monthly precipitation and runoff data in 1958-2011 were obtained from the Biliu River Reservoir administration. Month meteorological data were obtained from the China Meteorological Data Sharing Service System (http://cdc.cma.gov.cn/inex.jsp). The Digital Elevation Model (DEM) data $(90 \times 90 \mathrm{~m})$ were obtained from the CGIAR Consortium for Spatial Information (CGIAR-CSI) (http://srtm.csi.cgiar.org). Soil type and land use maps were obtained from the Data Center for Resources and Environmental Sciences, Chinese Academy of Sciences (http://www.resdc.cn/fist.asp).

\section{Code availability}

The calculate code of climate internal variability and ANOVA are according to the corresponding formulas, which has already described in this manuscript.

\section{Ethics approval}

ALL that data and analysis in this manuscript are ethics approval.

\section{Consent to participate}

This manuscript consent to participate.

\section{Consent for publication}

This manuscript consent to publication. 


\section{Acknowledgements}

This study was sponsored by the Natural Science Foundation of Shanxi Province, China. Grant No.201901D111060 and the Open Research Fund of State Key Laboratory of Simulation and Regulation of Water Cycle in River Basin, China Institute of Water Resources and Hydropower Research, Grant NO. IWHR-SKL-202103. We would also like to acknowledge the World Climate Research Programme's Working Group on Coupled Modeling, which is responsible for CMIP.

\section{References:}

Anjum M N, WahabA, Huggel C, Qamar M U, Hussain E, Ahmad S, Waheed A (2019) Simulation of the projected climate change impacts on the river flow regimes under CMIP5 RCP scenarios in the westerlies dominated belt, northern Pakistan. Atmospheric Research 227: 233-248. https://doi.org/10.1016/j.atmosres.2019.05.017

Abbaspour K C, Yang, Maximov I, Siber R, Bogner K, Mieleitner J, Zobrist J, Srinivasan R (2007) Modelling hydrology and water quality in the pre-alpine/alpine Thur watershed using SWAT, Journal of Hydrology 333:413-430. https://doi:10.1016/j.jhydrol.2006.09.014

Abbaspour K C, Johnson C A, van Genuchten M T (2004) Estimating Uncertain Flow and Transport Parameters Using a Sequential Uncertainty Fitting Procedure. Vadose Zone Journal 3:1340-1352. https://doi:10.2113/3.4.1340 Aryal A, Shrestha S, Babel M S (2017) Quantifying the sources of uncertainty in an ensemble of hydrological climate-impact projections. Theoretical and Applied Climatology 135: 193-209. https://doi.org/10.1007/s00704-017-2359-3

Byun, K, Chiu C M, Hamlet A F (2019) Effects of 21st century climate change on seasonal flow regimes and hydrologic extremes over the Midwest and Great Lakes region of the US. Science of the Total Environment 650: 1261-1277. https://doi.org/10.1016/j.scitotenv.2018.09.063

Bosshard T, Carambia M, Goergen K, Kotlarski S, Krahe P, Zappa M, Schar C (2013) Quantifying uncertainty sources in an ensemble of hydrological climate-impact projections. Water Resources Research 49:1523-1536. https://doi:10.1029/2011WR011533

Belcher S E, Hacker J N, Powell D S (2005) Constructing design weather data for future climates. Building Services Engineering Research and Technology 26: 49-61. https://doi.org/10.1191/0143624405bt112oa

Beven K, Binley A (1992) The future of distributed models: model calibration and uncertainty prediction. Hydrological Processes 6(3): 279-298. http:///doi/abs/10.1002/hyp.3360060305

Chen J, ST-Denis B G, Brissette F P, Lucas-Picher P (2016) Using Natural Variability as a Baseline to Evaluate the Performance of Bias Correction Methods in Hydrological Climate Change Impact Studies. American Meteorological Society 17: 2155-2173. https://doi: 10.1175/JHM-D-15-0099.1

Chawla I, Mujumdar P P (2018) Partitioning uncertainty in streamflow projections under nonstationary model conditions. Advances in Water Resources 112: 266-282. https://doi.org/10.1016/j.advwatres.2017.10.013

Chen S T, Yu P S, Tang Y H (2010) Statistical downscaling of daily precipitation using support vector machines and multivariate analysis. Journal of Hydrology 385(1-4): 13-22. https: doi:10.1016/j. jhydrol.2010.01.021

Deser C, Phillips A, Bourdette V, Teng H M (2012) Uncertainty in climate change projections: the role of internal variability, Climate Dynamic 38:527-546. http://doi 1007/s00382-010-0977-x

Doi Van, Kim M. J (2020) Projections on climate internal variability and climatological mean at fine scales over South Korea. Stochastic Environmental Research and Risk Assessment 34(7): p. 1037-1058. https://doi.org/10.1007/s00477-020-01807-y 
Evin G, Hingra B, Blanche, J Eckert N, Morin, Verfaillie (2019) Partitioning Uncertainty Components of an Incomplete Ensemble of Climate Projections Using Data Augmentation. Jounal of Climate 32:2423-2440. https://doi. 10.1175/JCLI-D-18-0606.1

Ficklin D L, Letsinger S L, Stewart I T, Maurer E P (2016) Assessing differences in snowmelt-dependent hydrologic projections using CMIP3 and CMIP5 climate forcing data for the western United States. Hydrology Research 47: 483-500. https://doi: 10.2166/nh.2015.101.

Frankcombe L M, England M H (2015) Separating Internal Variability from the Externally Forced Climate Response. Journal of Climate. 28: 8184-8202. https://doi: 10.1175/JCLI-D-15-0069.1

Gupta A, Govindaraju R S (2019) Propagation of structural uncertainty in watershed hydrologic models. Journal of Hydrology 575: 66-81. https://doi.org/10.1016/j.jhydrol.2019.05.026

Galavi H, Mirzaei M (2020) Analyzing Uncertainty Drivers of Climate Change Impact Studies in Tropical and Arid Climates. Water Resources Management 34: 2097-2109. https://doi.org/10.1007/s11269-020-02553-0 Hawkins E, Sutton R (2011) The potential to narrow uncertainty in projections of regional precipitation change. Climate Dynamic 37: 407-418. http://doi 10.1007/s00382-010-0810-6

Hingray B, Blanchet J, Evin G, Vidal J P (2019) Uncertainty component estimates in transient climate projections: Precision of estimators in a single time or time series approach. Climate Dynamic 4635-1. https ://doi.org/10.1007/s0038 2-019-04635 -1

Kujawa H, Kalcic M, Martin J, Aloysius N, Apostel A, Kast J, Murumkar A, Evenson G, Becker R, Keller L, Zischg A P, Mosimann M, Rössler O, Weingartner R, Martius O (2019) Large ensemble flood loss modelling and uncertainty assessment for future climate conditions for a Swiss pre-alpine catchment. Science of The Total Environment 693:133400. https://doi.org/10.1016/j.scitotenv.2019.07.206

Kim J, Tanveer M E, Bae D H (2018) Quantifying climate internal variability using an hourly ensemble generator over South Korea. Stochastic Environmental Research and Risk Assessment 32:3037-3051. https://doi.org/10.1007/s00477-018-1607-0

Li L, Diallo I, Xu C Y, Stordal F (2015) Hydrological projections under climate change in the near future byRegCM4 in Southern Africa using a large-scale hydrological model. Journal of Hydrology 528:1-16. http://dx.doi.org/10.1016/j.jhydrol.2015.05.028 Liu Y, Zhang J Y, Wang G Q, Liu J F, He R M, Wang H J, Liu C S, Jin J L (2012) Assessing the effect of climate natural variability in water resources evaluation impacted by climate change. Hydrological Processes 27(7):1061-1071. https://doi: 10.1002/hyp.9251. Lee M H, Bae D H (2016) Uncertainty Assessment of Climate Change Impacts on Hydrology: A Case Study for the Central Highlands of Vietnam. Procedia Engineering 154: 617-623. https://doi: 10.1016/j.proeng.2016.07.560. Lafaysse M, Hingray B, Mezghani A, Gailhard J, Terray L (2014) Internal variability and model uncertainty components in future hydrometeorological projections: The Alpine Durance basin. Water Resources Research 50(4): p. 3317-3341. https:// doi:10.1002/ 2013WR014897

Maher N, Lehner F, Marotzke J (2020) Quantifying the role of internal variability in the temperature we expect to observe in the coming decades. Environmental Research Letters 15:054014. https://doi.org/10.1088/1748-9326/ab7d02 Landcover changes on hydrology for the upper San Pedro watershed. Journal of Hydrology 407:105-114. https://doi:10.1016/j.jhydrol.2011.07.012.

757 Nóbrega M T, Collischonn W, Tucci C E M, Paz A R (2011) Uncertainty in climate change impacts on water 758 resources in the Rio Grande Basin, Brazil. Hydrology and Earth System Sciences 15: 585-595. 

N P (2019) Climate change impact on the hydrological budget of a large Mediterranean island. Hydrological Science Journal 6 :1190-1203. https://doi.org/10.1080/02626667.2019.1630741

Pesce M, Critto A, Torresan S, Giubilato E, Pizzol L, Marcomini A (2019) Assessing uncertainty of hydrological and ecological parameters originating from the application of an ensemble of ten global-regional climate model projections in a coastal ecosystem of the lagoon of Venice, Italy. Ecological Engineering 133:121-136. https://doi.org/10.1016/j.ecoleng.2019.04.011

Qin X S, LU Y (2014) Study of climate change impact on flood frequencies_A combined weather generator and hydrological modeling approach. American Meteorological Society 15: 1205-1219. https://doi: 10.1175/JHM-D-13-0126.1.

Qi W, Zhang C, Fu G T, Zhou H C, Liu J G (2016) Quantifying Uncertainties in Extreme Flood Predictions under Climate Change for a Medium-Sized Basin in Northeastern China. Journal of Hydrometeorology 17: 3099-3112. https://doi: 10.1175/JHM-D-15-0212.1.

Shi L, Feng P Y, Wan B, Liu D L, Cleverly J, Fang Q X, Yu Q (2020) Projecting potential evapotranspiration change and quantifying its uncertainty under future climate scenarios: A case study in southeastern Australia. Journal of Hydrology 584:124756. https://doi.org/10.1016/j.jhydrol.2020.124756.

Shen M, Chen J, Zhuan M J, Chen H, Xu C Y, Xiong L H (2018) Estimating uncertainty and its temporal variation related to global climate models in quantifying climate change impacts on hydrology. Journal of Hydrology 556: 10-24. https://doi.org/10.1016/j.jhydrol.2017.11.004. Schindler A, Toreti A, Zampieri M, Scoccimarro E, Gualdi S, Fukutome S F, Xoplaki E, Luterbacher J (2015) On the Internal Variability of Simulated Daily Precipitation, Journal of Climate 28:3624-3630. http://dx.doi.org/10.1175/JCLI-D-14- 00745.s1. Griensven Van, Meixne A T (2006) Methods to quantify and identify the sources of uncertainty for river basin water quality models. Water Science and Technology 53: 51-59. http://doi: 10.2166/wst.2006.007. Vaghef A S, Iravani M, Sauchyn D, Andreichuk Y, Goss G, Faramarzi M (2019) Regionalization and parameterization of a hydrologic model significantly affect the cascade of uncertainty in climate-impact projections. Climate Dynamics 53:2861-2886. https://doi.org/10.1007/s00382-019-04664-w.

Wang Q, XuY P, Xu Y, Wu L, Wang Y F, Han L F (2018) Spatial hydrological responses to land use and land cover changes in atypical catchment of the Yangtze River Delta region. Catena 170:305-315. https://doi.org/10.1016/j.catena.2018.06.022.

790 Wang Q, Xu Y P, Wang Y F, Zhang Y Q, Xiang J, Xu Y, Wang J (2020) Individual and combined impacts of future land-use and climate conditions on extreme hydrological events in a representative basin of the Yangtze River Delta, China. Atmospheric Research 23:104805. https://doi.org/10.1016/j.atmosres.2019.104805. Wu H B, Chen (2015) Evaluating uncertainty estimates in distributed hydrological modeling for the Wenjing River watershed in China by GLUE, SUFI-2, and ParaSol methods. Ecological Engineering 76:110-121 http://dx.doi.org/10.1016/j.ecoleng.2014.05.014. Wang B, Liu D L, Waters C, Yu Q (2018) Quantifying sources of uncertainty in projected wheat yield changes under climate change in eastern Australia. Climatic Change 151(2): 259273. https://doi.org/10.1007/s10584-0182306-z.

799 Wang F, Huang H G, Fan Y, Li Y P (2020) Robust Subsampling ANOVA Methods for Sensitivity Analysis of

800 Water Resource and Environmental Models. Water Resources Management 34: 3199-3217. 801 https://doi.org/10.1007/s11269-020-02608-2. 
Xue C, Chen B, ASCE M, Wu H J (2014) Parameter Uncertainty Analysis of Surface Flow and Sediment Yield in the Huolin Basin, China. American Society of Civil Engineers 19: 1224-1236. https://doi: 10.1061/(ASCE)HE.1943-5584 .0000909.

Yen H, Wang XY, Fontane D G, Harmel R D, Arabi M (2014) A framework for propagation of uncertainty contributed by parameterization, input data, model structure, and calibration/validation data in watershed modeling. Environmental Modelling \& Software 54: 211-221. http://dx.doi.org/10.1016/j.envsoft.2014.01.004.

Yu B, Li G L, Chen, S F, Lin H (2020) The role of internal variability in climate change projections of North American surface air temperature and temperature extremes in CanESM2 large ensemble simulations. Climate Dynamics 55:869-885. https://doi.org/10.1007/s00382-020-05296-1

Zhang Y Q, You Q L, Chen C C, Ge J (2016) Impacts of climate change on streamflows under RCP scenarios: A case study in Xin River Basin, China. Atmospheric Research 178-179:521-534. http://dx.doi.org/10.1016/j.atmosres.2016.04.018.

Zhang H, Huang G H (2013) Development of climate change projections for small watersheds using multi-model ensemble simulation and stochastic weather generation. Climate Dynamic 40:805-821. https://doi 10.1007/s00382-012-1490-1.

Zhang R, Corte-Real J, Moreira M, Kilsby C, Birkinshaw S, Burton A, Fowler H J, Forsythe N, Nunes J P, Sampaio, E, dos Santos F L, Mourato S (2019) Downscaling climate change of water availability, sediment yield and extreme events_ application to a Mediterranean climate basin, International Journal of Climatology 39:2947-2963. https://doi: 10.1002/joc.5994.

Zhu X P, Zhang C, Qi W, Cai W J, Zhao X H, Wang X F (2018) Multiple Climate Change Scenarios and Runoff Response in Biliu River. Water 10(2):690. https://doi:10.3390/w10060690.

Zhao F B, Wu Y O, Qiu L J, Sun Y H, Sun L Q, Li Q L, Niu J, Wang G Q (2018) Parameter Uncertainty Analysis of the SWAT Model in a Mountain-Loess Transitional Watershed on the Chinese Loess Plateau. Water 10: 690. http://doi:10.3390/w10060690.

Zhang L M, Yuan F, Wang B, Ren L L, Zhao C X, Shi J Y, Liu Y, Jianf S H, Yang X L, Chen T, Liu S Y(2021) Quantifying uncertainty sources in extreme flow projections for three watersheds with different climate features in China. Atmospheric Research 249:105331. https://doi.org/10.1016/j.atmosres 